WORKING PAPER NO. 9

Mar 1996

\title{
CIFOR's Research Programme on Conservation of Tropical Forest Genetic Resources
}

\author{
Timothy J.B. Boyle
}

\begin{abstract}
Summary
The research programme described is intended to comprehensively answer key questions relating to in situ conservation of genetic resources. Outputs will be in the form of models of how landscape processes affect genetic level processes, and in the form of management prescriptions or policy options. In the case of research on tools and methodologies, outputs will obviously be improved methods for assessment of genetic diversity.

There are strong links to various elements of CIFOR's research agenda. The links to socio-economic research of CIFOR's Policy and Social Science scientists are obvious and have been emphasised throughout. In addition, there are links to the Forest Ecosystem Management initiative under the Natural Forest Management Division, especially to the activities dealing with measurement of biodiversity and impacts of human activity on biodiversity, and to various activities in the Research Support Division. These include efforts to model the human-forest interface, and the development of GIS technology.
\end{abstract}

\section{CENTER FOR INTERNATIONAL FORESTRY RESEARCH}

office address: Jalan Gunung Batu 5, Bogor 16001 Indonesia mailing address: P.O.Box 6596, JKPWB, Jakarta 10065 Indonesia tel.: +62(251) 34-3652 fax: +62(251) 32-6433

email: cifor@cgnet.com 


\title{
CIFOR's Research Programme on Conservation of Tropical Forest Genetic Resources
}

\author{
Timothy J.B. Boyle ${ }^{1}$
}

\begin{abstract}
Summary
The research programme described below is intended to comprehensively answer key questions relating to in situ conservation of genetic resources. Outputs will be in the form of models of how landscape processes affect genetic level processes, and in the form of management prescriptions or policy options. In the case of research on tools and methodologies, outputs will obviously be improved methods for assessment of genetic diversity.

There are strong links to various elements of CIFOR's research agenda. The links to socio-economic research of CIFOR'S Policy and Social Science scientists are obvious and have been emphasised throughout. In addition, there are links to the Forest Ecosystem Management initiative under the Natural Forest Management Division, especially to the activities dealing with measurement of biodiversity and impacts of human activity on biodiversity, and to various activities in the Research Support Division. These include efforts to model the human-forest interface, and the development of GIS technology.
\end{abstract}

\section{Introduction}

Forests are the world's most important and valuable natural and renewable resource. However, this global treasure is in imminent danger of genetic erosion and increased vulnerability due to adverse abiotic and biotic stresses resulting from expansion of agricultural lands, urban and infrastructural development, water and air pollution, and global warming. There is therefore an urgent need for effective genetic conservation strategies to be developed and applied.

One of CIFOR's objectives is "to devise and promote more sustainable, equitable, and productive options for forest ecosystem management." Under this objective, one of the strategies is "the conservation and utilisation of forest genetic resources and biodiversity (CIFOR 1996). In line with its mission statement to "... contribute to the sustained well-being of people in developing countries ... through collaborative strategic and applied research ...", CIFOR has therefore been developing a collaborative research programme on conservation of genetic resources throughout the tropical regions of the world.

In the area of genetic resources, the most important strategic issues concern the conservation of genetic diversity. CIFOR has no comparative advantage in research on ex situ conservation, nor is ex situ conservation a viable option for forest genetic resources, except in emergency situations, or for germplasm of known, high value. Therefore, CIFOR's research programme on conservation of genetic resources is devoted entirely to in situ conservation.

Genetic resources was the first subject area in the CGIAR system to be organised into a Systemwide Programme. This means that CIFOR's work on genetic resources is not conducted in isolation from the other CGIAR Centers. In particular, IPGRI has also developed a programme on conservation of forest genetic resources. While CIFOR's and IPGRI's programmes differ in many respects, in the area of in situ conservation the two centres share common goals. In the interests of efficiency in pursuit of these common goals, CIFOR is taking the regional lead in South-East Asia, and IPGRI in Africa, with a shared responsibility for Latin America. Links with IPGRI, ICRAF, and other CGIAR Centers will also be strengthened through participation in the Inter-Center Working Group on Genetic Resources.

\footnotetext{
${ }^{1}$ With contributions from Abdou-Salam Ouédraogo (IPGRI), Peter Kanowski (Australian National University), Francis Yeh (University of Alberta), Andrew Young (CSIRO), Thomas Enters (CIFOR), Steve Harris and David Boshier (OFI)
} 


\section{Background}

The degradation and loss of tropical forests around the world is widely recognised as a problem of global significance. Whilst conversion of forest to other land uses, and non-sustainable exploitation of remaining forests may benefit national and local economies in the short term, there are longer-term negative consequences. At the national and local levels, there may be limited future supplies of firewood, construction timber and other wood and non-wood products, and changes to the local and regional climates. At the global level the negative consequences are related to changes in the global climate, especially the contribution of deforestation to climate warming, and losses of biodiversity, tropical forests being the most diverse terrestrial systems. These two issues are inter-linked - deforestation contributes directly to both global climate change and loss of biodiversity; conservation of tropical forests will ameliorate the climate and conserve biodiversity.

Efforts to conserve tropical forests require methods for assessing the current status of forests and monitoring changes over time. Levels of biodiversity provide one criterion for assessing the status of forests and sustainability of forest management. Levels of genetic diversity are potentially very useful early warning indicators of changes in biodiversity as a whole. This is because, in the hierarchy of biological organisation (Figure 1), genes operate at the smallest scale, but the most rapid rate. Changes to ecosystems usually (except for cataclysmic events) occur over many years, decades, or even centuries. Changes in species composition of ecosystems also usually occur over a time scale of years. Extinction is the final step of a long process of declining stocks and population viability. The addition of species diversity occurs through speciation or, more realistically, through migration. While the arrival of a migrant is an instantaneous event, the establishment of a viable population takes much longer. Changes at the genetic level are, however, much more rapid.

The "ecosystem" approach, involving conservation of target habitats, is generally accepted to be the most effective method for conservation of biodiversity. However, except in very rare instances, habitat does not consist simply of physical features. Habitat is predominantly biological, consisting of other organisms interacting with their physical environment. Trees, in particular, provide habitat for other species. Therefore, ecosystems (or habitat) cannot be conserved without conservation of their constituent species. Similarly, species cannot be conserved without conservation of the genetic diversity which allows them to adapt to a fluctuating environment.

While species extinctions are often the politically favoured focus of biodiversity loss, irreparable damage to biodiversity has been inflicted long before a species actually becomes extinct or extirpated from an ecosystem (Hartl and Clark 1989). Various factors can lead to extinction or extirpation, including direct exploitation, interference with demographic processes or habitat modification. Gilpin and Soulé (1986) reviewed the concept of minimum viable population sizes and the processes of species extinction. They proposed that the extinction process could proceed through different types of extinction "vortices". Depending on characteristics of the species biology and ecology, and external factors such as environmental stochasticity, one or other of their proposed vortices, or some combination, may lead to species extinction. Genetic processes, such as inbreeding and genetic drift, feature prominently in "driving" two of these vortices, which apply particularly at low population sizes. Gilpin and Soulé suggest that trees are particularly susceptible to these vortices, and this presumably applies especially to tropical trees, which usually occur in very small populations.

Even for organisms which fall into extinction vortices not driven by genetic processes, changes at the genetic level will be detected very quickly. There cannot be changes in population size or age structure without attendant changes in measures of genetic diversity. Indeed, population sizes can be stable or increasing while genetic diversity is being rapidly lost (Primack 1993). Population censuses or monitoring extinctions are therefore very poor methods of assessing loss of biodiversity, as the effects are only evident at a very late stage, when most of the damage has already been done. Change may be much simpler to detect by means of genetic diversity assessment than through some form of demographic monitoring.

Thus, research on the conservation of genetic diversity of tropical forest ecosystems can contribute both directly to conservation of genetic resources and to methods for "early-warning" monitoring of conservation of biodiversity, and of sustainability of forest management.

Loss of genetic diversity has direct and indirect consequences. If a disproportionate number of poorer genotypes are retained, as is possible through selective logging, the species may be less adapted to its environment, and/or inbreeding rates may increase, leading to greater probability of extinction (Murawski et al. 1994). Any reduc- 
tion in genetic diversity also reduces the capacity of species to respond to changing environments either at a global level, through climate warming, or locally, as the forest becomes more degraded and environmental conditions are thus modified (National Research Council 1991).

From an economic perspective, the loss of genetic diversity from species that have actual or potential commercial value, even if the species itself survives, is potentially far more damaging than extinction of many other species of little commercial value. This is because, as discussed above, the risk of future extinction is greatly increased, while the potential for genetic manipulation to produce improved varieties through breeding is lost (National Research Council 1991). Ecologically, the loss of genetic diversity of species significant for ecosystem functioning is far more significant than extinction of species having little ecological value (Primack 1993).

\section{Principles governing CIFOR's research on genetic conservation}

A major problem faced in developing a programme of strategic research on conservation of genetic diversity is the enormous numbers of species in tropical forests. This dictates that, rather than studying specific, economically important species, principles governing the conservation of genetic diversity in tropical forests are more likely to be revealed through the study of processes. In particular, research will focus on the interaction of processes at two scales - the landscape-scale processes that reduce genetic diversity, especially degradation (disturbance) and deforestation (fragmentation) - and the genetic-scale processes such as gene flow, inbreeding, genetic drift, etc. The interaction of processes at these two scales will depend on the biological and ecological characteristics of the organisms on which they are acting. Therefore, studies on these processes will include "model" species, not necessarily trees, which represent contrasting ecological approaches (or "life history characteristics") to maintaining genetic diversity. For example, model species may include those pollinated by small, less mobile insects (e.g., thrips), small mobile insects (small bees/wasps), large insects, bats, and possibly wind. Model species will also exhibit a variety of seed dispersal mechanisms (at least gravity/wind and bird dispersal), and will also be characterised by differences in terms of distribution (wide- spread versus clumped) and canopy position.

There have been relatively few such studies conducted to date, and those that have been undertaken have often been opportunistic or strictly applied in nature. Therefore there is a definite role for CIFOR.

Research on tropical forest genetic diversity has suffered in the past not only from a lack of funding or qualified institutions/individuals, but also from a lack of suitable techniques. Application of many of the advanced molecular marker techniques to tropical-forest species has only recently been attempted, and there remains a dearth of well-equipped laboratories and trained scientists in the tropics capable of conducting studies involving such techniques. Similarly, analysis of genetic data is relatively complex, requiring access to computers and specialised software. Both are difficult to procure for many tropical institutions. CIFOR will also conduct research on new, and more readily available tools, such as molecular marker techniques, improved computer programs and GIS, to improve the ability to analyse genetic diversity.

\section{Multi-disciplinarity}

Virtually all tropical forests are affected by economic (subsistence and cash-oriented) activities. Most forests are exploited by several user-groups or stakeholders and the balance of use by the various groups changes over time with resultant changing threats to biodiversity. Effective control over forest resources rests with the stakeholders and particularly with the resident population, individuals and communities that live in and around the forests, national parks or wilderness areas. In economic terms they are the providers of biodiversity conservation (Panayotou and Glover 1994) and it is their everyday activities which ultimately decide the fate of much terrestrial biodiversity. While the northern vision of an untouched wilderness has permeated global policies and politics in resource conservation for decades (Gómez-Pompa and Kaus 1992), it is obvious that tropical forests are anything but untouched and that conserving their biodiversity is largely a socio-economic issue.

Multi-disciplinary research is therefore essential for addressing many of the more complex problems of tropical forests, and is an integral part of CIFOR's strategy. Janssen and Goldsworthy (1995) discuss the concept and practice of multi-disciplinary research on natural resource management. They emphasise that suc- 
cessful multi-disciplinary research requires a shift from the traditional reductionist approach to research to more of a systems approach. They also discuss the four types of multi-disciplinary research (additive, integrated, non-disciplinary and synthetic) in terms of suitable problems to be studied by each type, and complexity of planning and management. They propose that integrated multi-disciplinary research is best suited to the development of modified production systems, and a synthetic approach to the development of new methodologies, though such an approach is very difficult to manage.

The programme of work on genetic conservation described below is intrinsically multi-disciplinary, as it has relevance to higher levels in the hierarchy of biological organisation. Also, because of the human impacts on forests, any programme of research dealing with conservation inevitably involves a role for the social sciences. Wherever possible, truly integrated multi-disciplinary research or, at a minimum, additive multidisciplinary studies will be promoted. Although all projects dealing with processes affecting genetic diversity have socio-economic components, as the processes are the results of human activities, this is particularly true for non-logging disturbances and fragmentation, and for the research on GIS as a tool (see next section).

\section{Research projects}

CIFOR's research projects on genetic conservation will focus on the two landscape-scale processes that cause loss of biodiversity, namely forest degradation and deforestation. Anthropogenic forest degradation is the result of human activities within the forest, hereafter referred to as "disturbance". There are many types of disturbance, including felling of trees, harvesting of non-timber forest products, grazing and burning. Of these, commercial logging is a disturbance that has a very high public and political profile, and so will receive particular attention in studies on disturbance (Figure 2).

Deforestation is rarely complete, but usually results in a landscape containing fragments of the original forest cover in an agricultural, secondary forest or forest plantation matrix. The impact of fragmentation will therefore constitute another significant research effort (Figure 2).

Research on tools for measuring genetic diversity actually provide a link to CIFOR's research effort on utilisation of genetic resources (not described in this document), as many of the tools can be equally used in tree improvement programmes. There are also obvious links between the boxes in Figure 2. For example, in many cases disturbance and fragmentation go hand-in-hand, while GIS is a potentially valuable tool for studying both processes. However, for simplicity both in managing research projects and in diagrammatic representation, these subject areas are considered independently.

As is indicated in Figure 2, CIFOR and IPGRI share a common interest for some research topics. These include the studies of the impact of landscape level processes on genetic processes and the use of GIS as a conservation tool. The two centres will work closely together on these issues, with common goals. Taking advantage of geographic location, CIFOR will take the lead on projects in Asia, IPGRI in Africa, and the two will share the role in Latin America and the Caribbean.

Research on processes affecting genetic

\begin{tabular}{|lc|c|}
\hline Ecosystems & Large & $\underline{\text { Size }}$ \\
Species & Slow & \\
Genes & Small & Fast \\
\end{tabular}

Figure 1. Relationship between hierarchical levels of biological organisation and scales of space and time. 


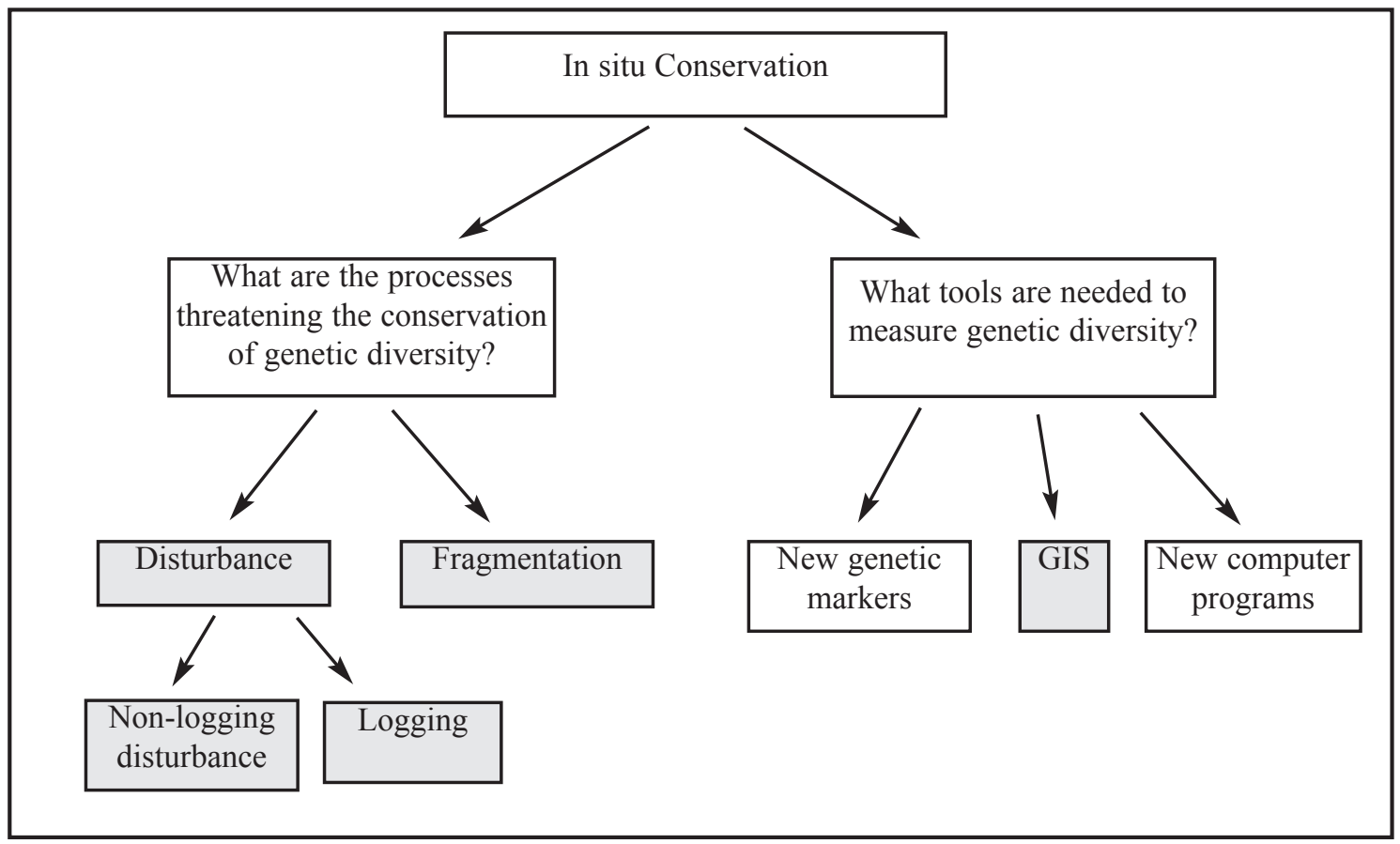

Figure 2. Diagramatic representation of CIFOR's research programme in conservation of forest genetis resources. Topics in shaded boxes indicate research projects on which CIFOR and IPGRI collaborate.

diversity will utilise the most appropriate existing tools for assessing genetic diversity. In most cases these will be molecular markers, especially isozymes. More sophisticated DNA markers will be used where facilities and expertise exist, and where the problems being addressed are relevant to the properties of different types of DNA markers. In other circumstances, quantitative genetic variation may be measured by means of nursery or field trials.

Each of the six research areas is described in more detail below.

\section{Non-logging disturbance}

It has long been recognised that in situ conservation is inevitably affected by ecological, economic, political and social circumstances (Frankel, 1974; cited in Shafer, 1990). However, biodiversity conservation interests are still compartmentalised. Conservation and rural development strategies are viewed as two separate issues with conservation frequently being treated as if it unrelated to human beings and their activities. As a result, even technically well-designed conservation strategies based on biological concepts and inventories have little chance for long-term success.

Numerous examples show (Braatz 1992; Fairhead and Leach 1993; McNeely 1993;
Pinedo-Vasquez and Padoch 1993) that unless affected forest users can gain economic benefits from conservation activities or are compensated for their loss, there is little likelihood that effective long-term in situ conservation can be achieved (Vanclay 1992; Wells and Brandon 1993). Marketisation, modernisation and marginalisation already force local people to engage in activities that erode the once sustainable management systems (see for example, Utting 1993; Rajasekaran and Warren 1994). Parks and reserves are not viable if they exclude resident populations, both physically and economically (Woods, 1994).

To increase the effectiveness of conservation requires an improved understanding of the impacts of various activities on both the biological resource and on the livelihoods of local people and industries. This means that research needs to target the relationship between economic activities and their resultant impacts on and threats to biodiversity as shown below (Figure 3) in a conceptual model of human activities on biodiversity. This includes the close investigation of the direct (proximate) and indirect (underlying) causes of the threats (see two left boxes) and the examination of the resulting disturbances and their effects on biodiversity erosion (the two right boxes). Answering the question about who gains and who loses from actions leading to the threats in turn provides the opportunity to reverse the process for providing insights into the distribu- 


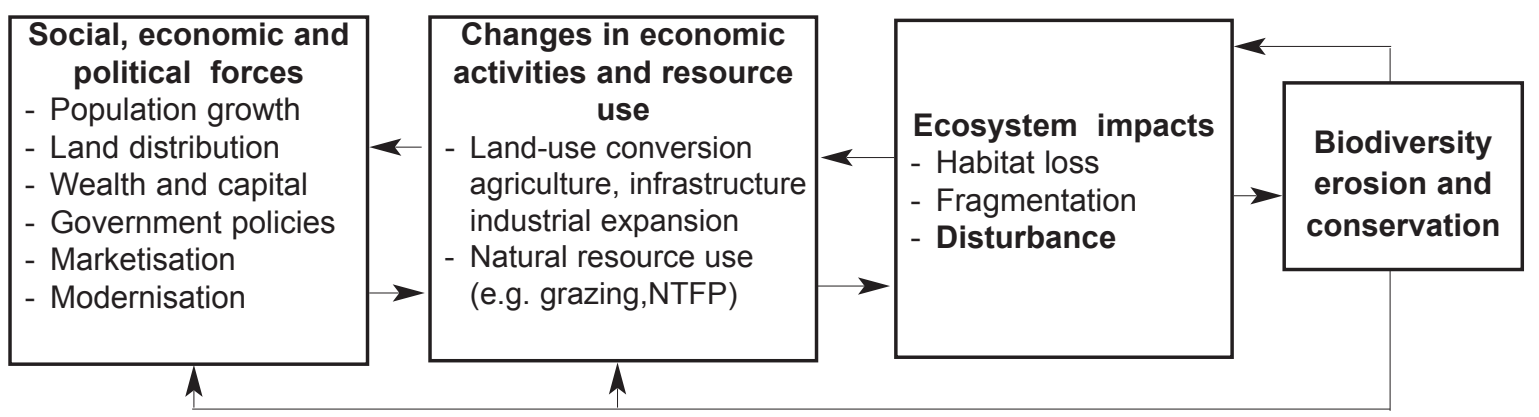

Figure 3. The inter-relationship between social, political and biophysical processes in determining the fate of biodiversity (adapted from Machlis, 1992).

tion of costs and benefits of hypothetical conservation activities.

As stated above, many integrated conservation projects implemented in areas of high biodiversity have had little success because the link between economic activities and resource conservation had received insufficient attention. Research has followed suit in compartmentalising conservation related issues and the shortcoming of this approach is represented graphically in Figure 4. If only genetic data is collected on the impact of disturbance on genetic resources (Figure 4a), the consequences of shifting the disturbance intensity through management restrictions cannot be anticipated, as the significance to local people of such a shift cannot be predicted. Only through multi-disciplinary research (Figure $4 b)$ can a complete understanding of the relationship between disturbance and genetic diversity be gained. This requires that the response of "model" species, representing different reproductive ecologies and economic uses, be studied over a gradient of different human activities, and that the economic significance of, and underlying driving forces resulting in these activities be understood. It should be emphasised that the actual impacts of disturbance will vary from species to species, as shown in Figure $4 \mathrm{a}$ - the consequences will not be felt equally by all species.

Only if the relationship between the underlying causes of human behaviour and the resultant impacts on biodiversity is understood can effective conservation strategies be efficiently designed (Boyle and Sayer 1995). Furthermore if, for policy reasons, restrictions are placed on use of the forest by local people in order to promote conservation, only through an understanding of this relationship can realistic incentives (financial or otherwise) be developed to provide benefits to local populations while promoting conservation. Without realistic incentives, as has been seen in so many cases of "paper parks", local people become alienated from the conservation goals of the imposed management system.
The result will usually be antipathy, or even antagonism towards the resources targeted for conservation. Although there are few examples of realistic compensatory incentives being offered to encourage conservation, the CAMPFIRE initiative in Zimbabwe is one such scheme (Scoones and Matose 1993).

\section{Objectives}

To contribute to more effective biodiversity conservation of tropical forest ecosystems by developing a generalisable methodology for assessing, monitoring and forecasting the impacts of conservation policies and practices on forest-dependent people and industries, and for assessing, monitoring and forecasting the impacts of economic activities, including the use of non-wood forest products, on forest ecosystems. This will be achieved by:

a) examining the underlying forces determining economic activities in tropical forest ecosystems, and quantifying the relative importance of those activities to household incomes;

b) determining the effect of intensity and type of disturbance (past and present economic activities and management systems), and environmental and ecological factors on the amount and structure of genetic diversity of model species at various disturbance intensities; and

c) assessing the socio-economic consequences of policies designed to change disturbance regimes.

\section{Methodology}

Using aerial photos, time series data of land-use changes in a number of countries with a focus on forest cover will be developed and analysed. Depending on the human resources and information available, the analysis with also cover forest disturbance and resultant composition changes. It will be complemented with data series on population growth, changes in accessibility and other such historical data to model the socio-economic 


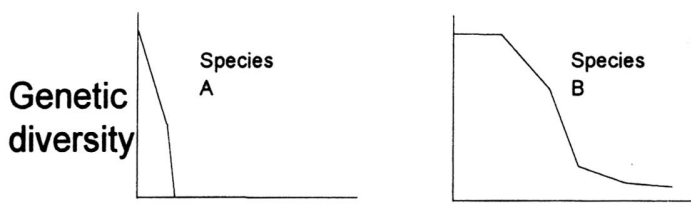

Disturbance

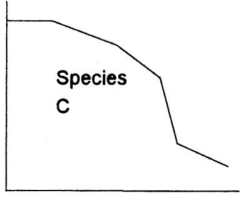

Figure 4a

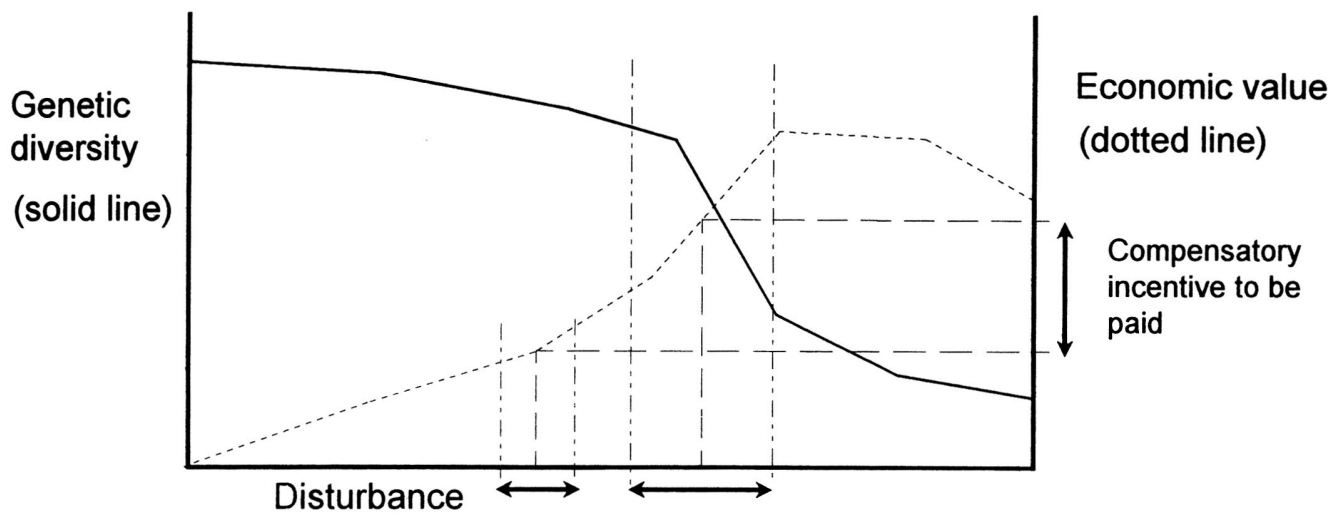

$\begin{array}{ll}\begin{array}{l}\text { Zone of actual } \\ \text { management }\end{array} & \begin{array}{l}\text { Zone of optimum } \\ \text { management }\end{array}\end{array}$

Figure 4b

Figure 4. In Figure 4a, possible relationships between intensity of disturbance (x axis) and genetic diversity (y axis) are shown for four possible "model" species. Species A is highly sensitive to disturbance, and can only be conserved in strictly protected areas. Species D is sensitive to disturbance (or may actually benefit), while Species B and C exhibit different buffering capacity and threshold tolerance levels. However, only through the multi-displinary research that yields Figure $4 \mathrm{~b}$ can the consequences of altering disturbance intensities be fully understood, and socially sensitive conservation strategies designed. Disturbance is measured in relative, rather than absolute terms, using an undisturbed location as the reference point.

forces which have affected the forest resource in the past. Oral histories may also be used to fill gaps and to gain an understanding of various stakeholders' perspectives of land cover changes and their causes. The objective of this activity is to provide baseline information particularly on the historical dimension of land-use changes and resource use.

Figure 5 shows one area proposed for this research. The five plots selected to represent a gradient of disturbance are distributed over a distance of about $18 \mathrm{~km}$, and each plot is between 40 and 100 ha. Three nearby villages are also shown. The economic activities of residents of these, and possibly other nearby villages, would be studied within the entire research area, i.e. up to about $15 \mathrm{~km}$ into the forest, or as distant as economic activities are found to occur.

Other socio-economic research activities are complementary and are designed to quantify the contributions of various forest products to livelihoods. They are designed to give an overview of present forest-related activities, including not only harvest of directly used products, but also grazing, burning, etc. They include the identification and description of policies which have promoted sustainable forest resource use and management on one hand, and encouraged forest degradation and accelerated deforestation on the other. User group surveys and key informant interviews will be conducted to gain an insight into forest resource use. Following Melynk (1994), data on the products used, seasonality of products, estimates of amounts harvested, estimate of amounts sold, perceptions of product availability, and priorities of communities with regard to these products and their habitats will be collected to estimate the contributions of forest species and ecosystem diversity to rural livelihoods.

In a most crucial component of the research the perspective will be widened to other components of livelihood strategies with a particular emphasis on agricultural and off-farm income generating activities. Particular emphasis will be given to the socio-political and economic forces which shape the decision making on economic strategies of rural populations. 


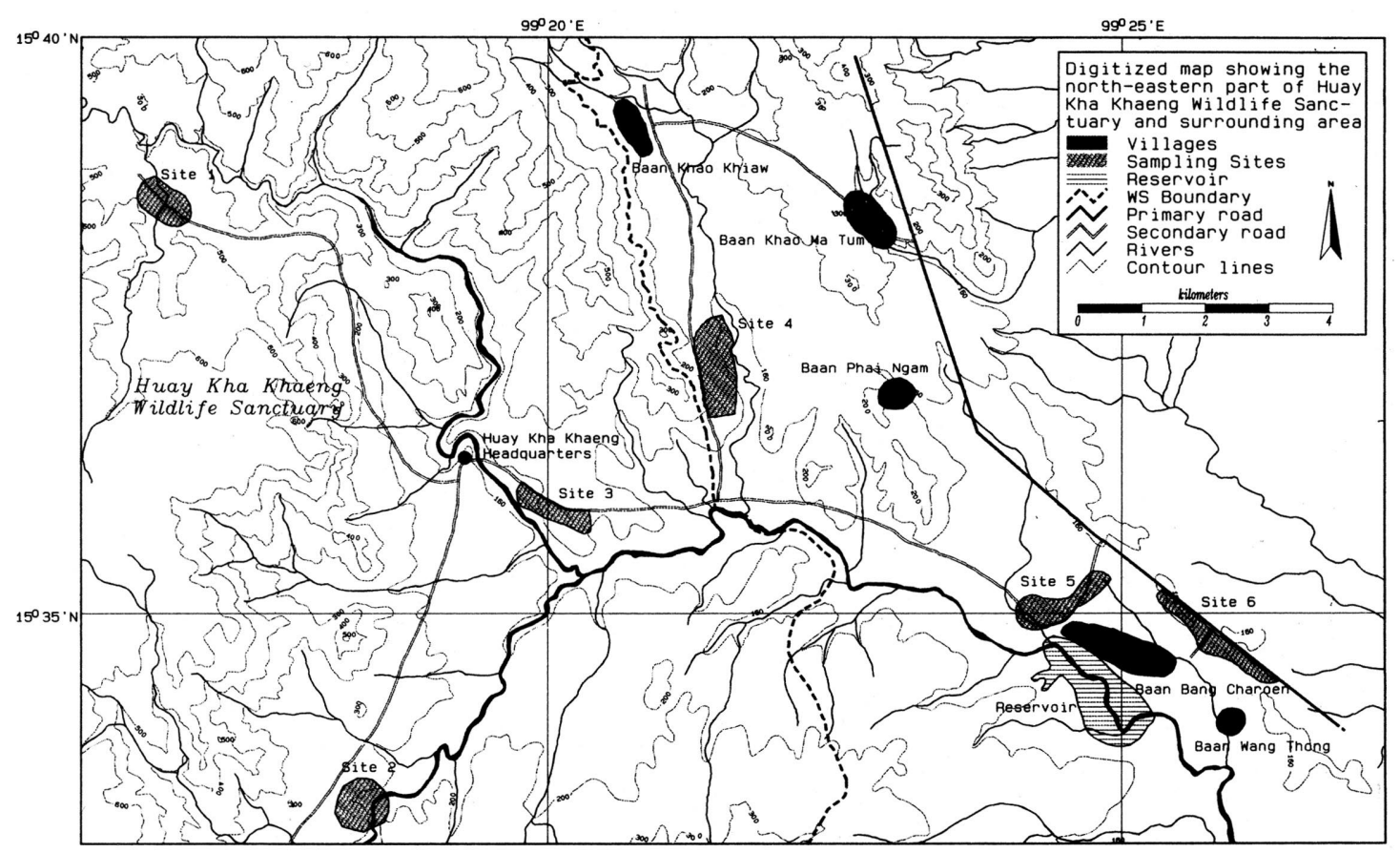

Figure 5. Locality of research sites in Thailand on non-logging disturbance. The scale is approximately 1:120,000. Five sample plots are shown (dark shading and dotted boundary) and three nearby villages (shading with solid boundary). The total area shown is approximately $20 \times 12 \mathrm{~km}$.

To assess the impact on biodiversity, each "model" species will be sampled on two or more sites in each participating country, consisting of a gradient of sub-sites subjected to different intensities and/or with a different history of disturbance. Thirty to fifty mature individuals will be sampled for each species in each population in order to allow estimation of genetic diversity. If seeds are available, they will also be collected to facilitate interpretation of genetic variation, and to allow estimates of mating system parameters. Each individual of every species will also be mapped, measured and tagged, and basic environmental data will be collected for each site to provide the basis for subsequently relating observed genetic diversity to environmental variables, and to quantify the type and intensity of disturbance.

Genetic diversity and genetic structure parameters will be estimated by means of isozyme analysis. The use of several different biochemical and genetic techniques (e.g. isozymes, ran- dom amplified polymorphic DNAs [RAPDs] and restricted fragment length polymorphisms [RFLPs]) in different labs is one of the reasons why data comparability for genetic diversity studies is so difficult. The comparison of data from isozyme analysis with the data from RAPDs may also be undertaken using the same experimental material.

\section{Logging}

The assertion is often made that selective logging is detrimental to genetic diversity. For example, Panayotou and Ashton (1992: 193) conclude that "[1]ogging, even when selective, and conservation of genetic resources are ... incompatible". The reasons they provide in support of this conclusion is that the age structure of the forest is disrupted, leading to progressively smaller "islands" of mature phase and that, together with increased inbreeding, characteristic species of 
mature forest cannot survive. Others have proposed that the disproportionate removal of genetically superior individuals adversely affects the genetic quality of the remaining and subsequent regenerating stand.

These problems are summarised in Figure 6, where the process of genetic erosion due to selective logging is represented. However, also indicated, to the right of the dotted line, are reasons why genetic diversity might not be lost. These are discussed in more detail below.

a) Preferential removal of superior genotypes.

Trees are selected for logging based on their phenotype. There are three reasons why a tree might be big, and therefore a superior phenotype - because it is old, because it is growing on a favourable microsite, or because it is genetically superior. The correlation between superior phenotypes and superior genotypes is high only when heritability is high. Heritability estimates for characteristics that constitute superior traits for logging, e.g., diameter and volume, are almost inevitably low, even under favourable conditions of even-aged plantations (Boyle et al., in press). In the highly unfavourable conditions of uneven-aged natural forests, heritability will be extremely low, so removal of superior phenotypes is unlikely to lead to differential removal of superior genotypes. In any case, species such as dipterocarps tend to flower profusely only after achieving a "mature" crown architecture associated with full overhead light. Therefore, the upper canopy trees, which are the ones to be logged, will have already contributed to the regenerating forest.

Their progeny will be found as suppressed seedlings, which will benefit from increased light caused by crown openings.

b) Increasingly isolated "islands" of mature phase. Although the forest post-logging will reflect characteristics of forest at an earlier successional stage, immature individuals of commercial species, together with rejected commercially sized individuals (e.g. due to rotten boles) will remain. As mentioned above, the regeneration originating from the logged trees will also remain. Too rapid cycles of logging will tend to erode genetic diversity, but this is a management/policy, rather than a biological, issue.

c) The reduced size of the reproductively mature

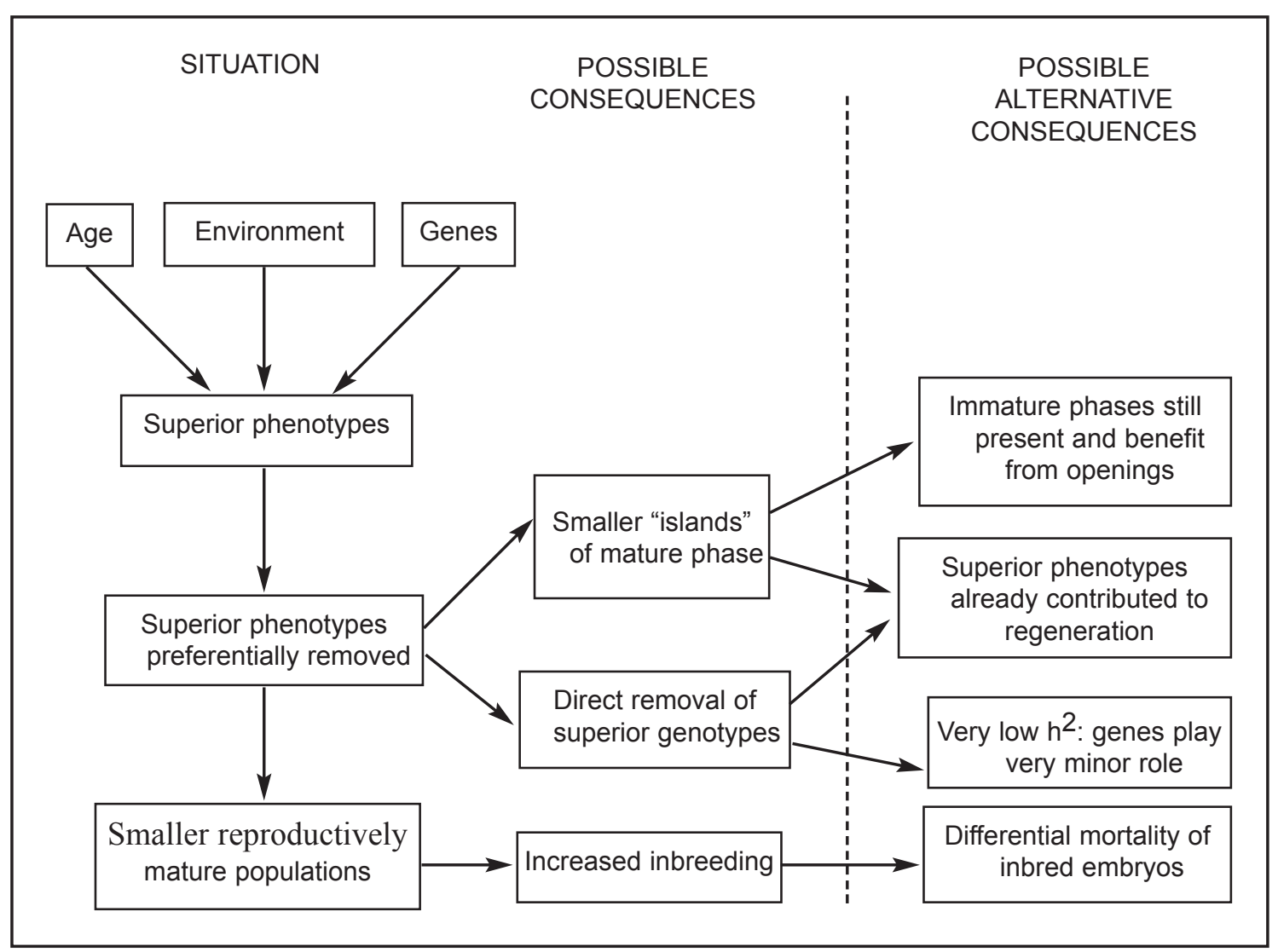

Figure 6. Possible impacts of selective logging on genetic diversity, and possible alternative consequences. Heritability $\left(\mathrm{h}^{2}\right)$ is the ratio of genetic to phenotypic variance, a measure of the strength of genetic control of a trait. 
population following logging may result in increased inbreeding, and this has been demonstrated for Shorea megistophylla by Murawski et al. (1994). Inbred embryos may suffer disproportionately higher mortality than outbreds and will also have to compete with the advanced regeneration.

Genetic impacts may also be expected to vary by species, related to reproductive ecology. Several species will therefore be used as "model" species. The final species selection will be based on field observations of species that are flowering heavily at the time of collection, and producing a high proportion of germinating seed. However, an attempt will be made to identify species that are common and widespread, common and clumped, and less common but widespread.

To increase the proportion of commercial species of harvestable size, large non-commercial species are poisoned. Often, in an effort to conserve bio- (i.e. species) diversity, trees of noncommercial species less than a threshold diameter are not poisoned, and poisoning proceeds "top-down", i.e. the largest trees are poisoned first, and this proceeds until the target reduction in basal area has been achieved, after which no smaller trees are poisoned.

The direct impact of one poisoning treatment on species and genetic diversity is not likely to be great, as most species have an inverse-J curve of tree size to frequency (i.e., relatively few big trees are poisoned, leaving many smaller trees surviving). However, longer-term impacts of repeated cycles of logging and poisoning could be much more severe if the species involved are unable to attain a sexually mature size, and thus contribute to a new generation of regeneration, before being poisoned.

The question is therefore one of reproductive biology. Small, understorey species, that typically reproduce under shade will be less affected and, in any case, will not often be the subject of poisoning. However, slow-growing, late-maturing upper canopy species are most likely to suffer in the long-term.

Changes in genetic diversity as a result of poisoning can be investigated in the same way as the impact of logging on commercial species using "model species", which in this case should be the slow-growing, late-maturing species that would appear to be most at risk. The future development of small diameter trees to sexual maturity prior to the next harvesting cycle can be assessed by studies of growth rates following poisoning.

Finally, if operational-scale forest management is to be able to include genetic conservation as a feasible management goal, it will be important to develop a better understanding of genetic diversity at two levels:

a) the localised impact on genetic diversity of forest management operations, such as selective logging and poisoning; and

b) the spatial arrangement of genetic diversity on a landscape scale.

Only with an adequate understanding of these issues can management prescriptions be developed. Research associated with testing the impact of logging on both commercial and noncommercial species will provide much of the information required to address the first of these two issues. However, there has been little work to date on the second issue. One problem is the usual one for genetic research that, with so many tree species (not to mention non-tree species), landscape-level patterns of genetic diversity will almost certainly vary among species, making generalisations very difficult. However, GIS offers a tool to investigate principles behind spatial variation in genetic diversity. For example, there may be correlations between species diversity and genetic diversity within species. From population genetic and ecological theory, it is possible to construct a hypothesis that, in regions of high species diversity, genetic diversity within any one species may be less than average, whereas in areas of lower species diversity, genetic diversity for the dominant species may be greater than average. If such relationships exist, then it would be possible to adapt management prescriptions to take account of spatial differences in genetic diversity. There are clear links here with the research on GIS as a tool.

Although less obvious than research on nonlogging disturbance (see above) and GIS (below), there are socio-economic issues relevant to this research. For example, changes to logging prescriptions in order to conserve genetic diversity may have, or be perceived to have, adverse consequences on the profitability of logging, and indirectly on the local people hired for this purpose. Tsai and Yuan (1995) have conducted some preliminary research on this topic in peninsular Malaysia. They suggest that as long as changes to prescriptions for individual species do not severely affect total yield (i.e. some diameter limits may go down, while others go up), logging companies will find such changes acceptable.

\section{Objectives}

a) To assess the impact of selective logging on genetic diversity, effective population sizes, and inbreeding rates of commercial species 
b) To assess the impact of selective logging on adaptive characters of commercial species

c) To assess the impact of forest management practices, such as poisoning, on the long-term genetic conservation of non-commercial species

d) To investigate the potential to develop operational-scale prescriptions for sensitive management of genetic diversity in commercial logging operations.

\section{Methodology}

a) Direct impacts on genetic diversity. Molecular markers provide direct estimates of gene frequencies, and can be assessed rapidly. However, some markers consist of single gene loci, or are simply random segments of DNA, which may or may not be representative of the whole genome. Morphometric traits are often polygenic and adaptively significant, but are time-consuming to assess. A combination of techniques is, therefore, most useful in developing a comprehensive assessment of changes in genetic diversity.

Large experimental plots will be used, in which the impacts of selective logging will be compared with unlogged controls. All individuals having a diameter greater than $30 \mathrm{~cm}$ in each plot representing the two treatments will be sampled by collection of vegetative material. The material will be used for isozyme and RFLP analyses. Data from the control plot can be used to model the impact of logging, whereas data from the logged plot will provide a direct estimate of impact (which may differ from expectations derived theoretically from the control plot due to the loggers' right to reject trees marked for felling if they believe the tree to be hollow, or too difficult to fell).

For morphometric analyses, in each treatment, approximately 50 seeds will be collected from 12 trees. Seedlots will be kept separate by maternal tree, and transferred immediately to the nearest operational nursery. When the seedlings are of a transplantable size, they will be established in a field trial close to the experimental area. Single tree plots of the 24 seedlots, with nominally 30 replications, will be established, and subsequently monitored for survival and growth.

Twenty young seedlings ("wildings") will also be collected from each of the two treatments by transplanting into pots, and transferred to the nearest facility capable of producing rooted cuttings. Serial cuttings will be taken and hedged, in order to generate 30 ramets from each ortet, which will also be established in a local field trial, and assessed as for the seedlings.

b) Inbreeding. Inbreeding may occur through selfing or mating among related individuals. A reduction in the density of sexually mature individuals may therefore be expected to increase inbreeding rates in the resulting embryos. However, subsequent natural selection and differential mortality during germination and early survival of seedlings may eliminate any effect found in the embryos. Therefore, both embryos and young seedlings will be used to estimate mating system parameters.

All possible maternal and paternal genotypes will have been established during the study of direct impacts. Therefore, 30 germinating seeds will be collected from nearby 25 putative maternal trees in each treatment. These will be used for isozyme analysis to estimate mating system parameters and confirm maternal identity. In addition, first year seedlings from this year's seed crop will subsequently be sampled and assessed in the same way.

c) Non-commercial species. For model species, all individuals greater than $10 \mathrm{~cm}$ diameter in the control and systematic treatment plots will be sampled, and their genotypes assayed by isozyme analysis. In each treatment, growth of 15-20 individuals in the $10-20 \mathrm{~cm}$ size class will be monitored over several years by means of diameter growth bands and periodic measurements of height. Flowering by all individuals in both treatments will also be monitored.

\section{Fragmentation}

Most research into the biological effects of ecosystem fragmentation for plants has been of an ecological nature, concentrating on changes in species richness and community dynamics (Meave et al. 1991, Young and Mitchell 1994). Much of this work has involved testing various aspects of Island Biogeography Theory (Helliwell 1976). More recently however, attention has been drawn to the possible genetic consequences of fragmentation and the implications for plant conservation (Billington 1991; Ledig 1992).

Direct effects of ecosystem fragmentation on plants include loss of populations, reductions in remnant population sizes, changes in densities of reproductive individuals and increased isolation of remnant populations. Based on this, the general prediction has been that fragmentation will 
be accompanied by an erosion of intra-specific genetic diversity through the generation of genetic bottlenecks, the reduction of inter-population gene flow, increased random genetic drift and elevated levels of inbreeding (Young 1995). In the short term, loss of individual genetic diversity (heterozygosity) may reduce individual fitness and, through this, lower population viability. In the longer term, lowered population-level genetic diversity (polymorphism and allelic richness) will limit the ability of a species to respond to changing selection pressures, thus reducing its evolutionary potential (Frankel 1970).

There is a limited amount of work being carried out at present to obtain hard data on intraspecific tree genetic diversity under conditions of habitat fragmentation, and most of the research is restricted to temperate regions (Young and Boyle, in press). For species of eucalypts in remnant vegetation different conservation strategies were recommended depending on population structure (Moran and Hopper 1987). Young and Merriam (1995) showed populations of Acer saccharum in mosaic fragments to be more diverse than those in continuous forest, although extreme spatial separation led to a reduction in genetic diversity. Ackerly et al. (1990), working on five dioecious canopy trees (Myristicaceae) in Central Amazon, showed very small effective breeding populations due to low reproductive densities, skewed sex ratios and overlapping generations. They concluded that fragmentation placed such species at great risk, due to reduced gene flow. Murawski and Hamrick (1991) found higher levels of genetic diversity in species classified as common, compared to uncommon species, in Panamanian rain forest. They concluded that uncommon species have less genetic variation than common species, due to low effective population size causing genetic drift. Genetic diversity of the uncommon species was however not as low as their effective population size would indicate, possibly due to long-distance pollen dispersal between widely separated individuals.

A significant question is: To what degree are initial sampling and genetic drift responsible for observed reductions in remnant population genetic diversity? If reductions in allelic richness are primarily attributable to initial sampling effects, then further losses due to genetic drift may still be expected, and current levels of diversity may provide little indication as to the long-term potential of remnant populations to maintain genetic diversity. However, if remnants have already reached a genetic drift/mutation balance, current diversity may be a useful indicator of future evolutionary potential. In the case of Eucalyptus albens,
Prober and Brown (1994) suggest that the relatively few generations that have passed since fragmentation means that the loss of alleles in small populations is most likely the result of a genetic bottleneck at the time of fragmentation. It is possible that this is the case for all of the species examined so far which are exclusively perennials.

Intriguingly, some data provide evidence for the existence of fragmentation thresholds, with regard to remnant population size and isolation, below which reductions in genetic diversity are apparently not encountered. For example, the relationship between population size and allelic richness for Scabiosa columbaria suggests that remnant populations larger than 200-300 individuals maintain high diversity, while those smaller than this do not. Similarly, for Eucalyptus albens, remnant populations of about 500 reproductive individuals or more have high allelic richness, while smaller populations exhibit fewer alleles. In terms of isolation thresholds, small $(<500$ reproductive individuals) remnant populations of $E$. albens isolated from other populations by less than $250 \mathrm{~m}$ exhibited high allelic richness, despite their small size. Presumably this reflects the maximum inter-population distance over which pre-fragmentation levels of gene flow can be maintained for this species. This kind of information provides valuable guidelines for the management of ecosystems which are currently subject to fragmentation, allowing population size and isolation limits to be set such that there is a reasonable chance of maintaining genetic diversity.

One problem in studying the impacts of fragmentation on genetic diversity are the multitude of factors influencing the outcome. In addition to fragment size and distance of isolation, discussed above, numerous other factors will affect rates of gene flow, and consequently genetic drift. These include:

a) Ecology. Species confined to narrow ecological niches, which may therefore tend to be restricted to relatively small isolated patches, even in continuous forest, may be relatively unaffected by fragmentation, especially if their particular microsite-types are not directly removed. Certainly, the initial sampling effect will be small, and the subsequent fate of genetic diversity will depend on other factors discussed below. In contrast, generalist species, which may have been widespread prior to fragmentation, are more likely to suffer from initial sampling effects.

b) Reproductive ecology. For animal pollinated and dispersed plants, gene flow will be 
reduced if inter-population distances become greater than the home ranges, or gap-crossing ability, of pollinator or disperser guilds (Powell and Powell 1987). For wind-pollinated and dispersed species increased interpopulation distances may reduce gene flow directly.

c) Matrix type. The gap-crossing ability of a species will depend on the nature of the gap. A matrix of grassland is likely to present a very different habitat quality from secondary (scrub) forest, or plantations, to pollinator and disperser guilds. This effect has been observed in restoration of deforested lands, where the artificial establishment of woody food/roost species has greatly enhanced seed dispersal and the establishment of regeneration of natural woodland species on abandoned grazing lands in Costa Rica (Brenes Varela 1994; Tenenbaum 1994)

d) Landscape pattern. Most research has concentrated on the classical "island" form of fragmentation. However, in some landscapes, such as in many parts of Central America, surviving fragments are restricted to river valleys and thus form a dendritic pattern, in which gene flow along fragments may be relatively unaffected, but gene flow across the intervening watershed may be much reduced. Hence, in addition to a potential overall reduction in genetic diversity, and changes in population genetic structure, there may also be a dramatically altered spatial arrangement of genetic diversity (Figure 7).

e) Initial density of individuals. Species which tend to be found at low densities are more likely to be reduced to non-viable effective population sizes as the intensity of fragmentation increases. On the other hand, species occurring at highly variable densities, are more likely to suffer a reduction in genetic diversity through the sampling effect of deforestation.

f) Time/variance. Most studies of fragmentation treat time as a relatively simple factor, such that with increasing time since fragmentation, the impacts of the event will have a greater impact. However, in addition to possibly reducing mean levels of gene flow and inbreeding, the variance of these processes is also likely to increase. Possibly, a fragment is at such a distance of isolation, and is located in such a matrix, that no effective gene flow occurs for a number of years, but optimum

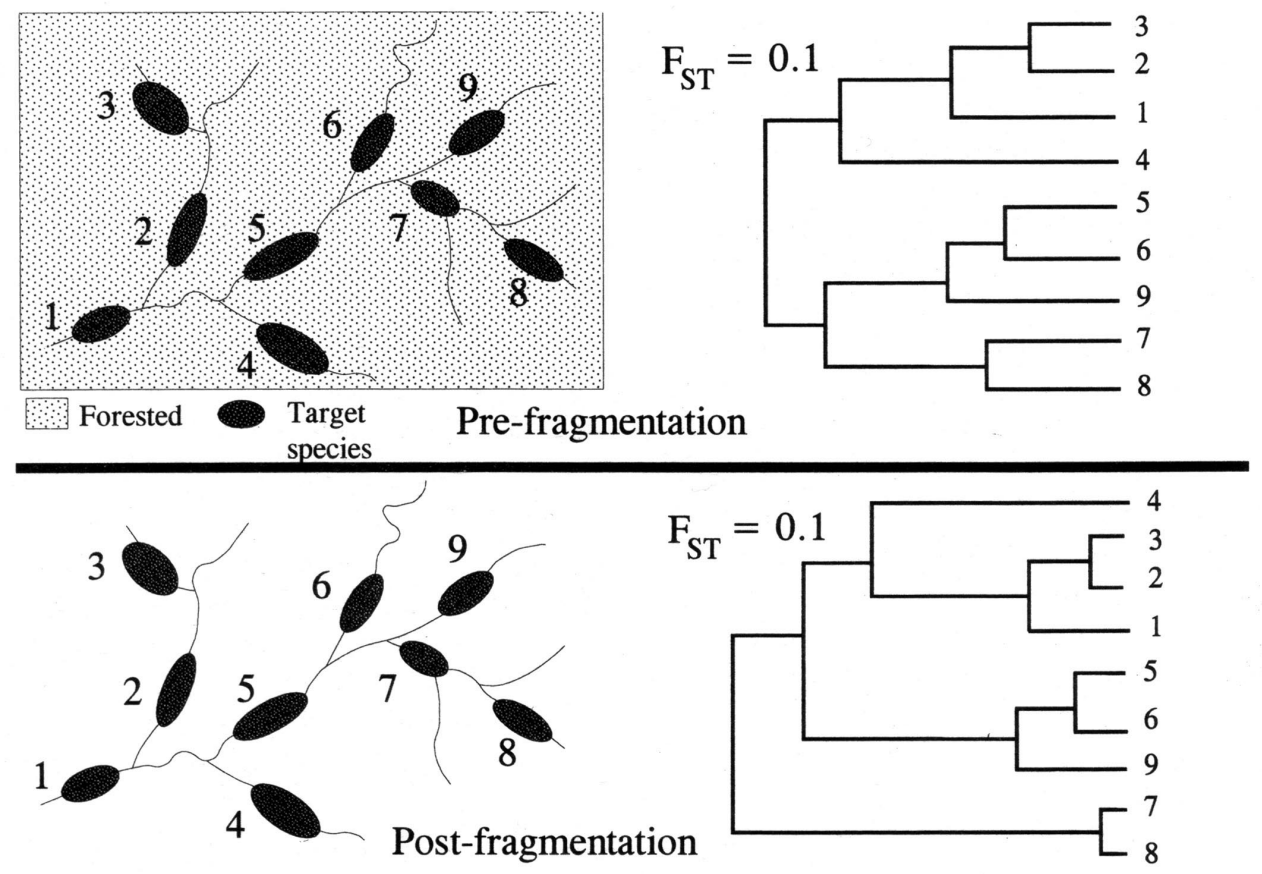

Figure 7. An example where landscape pattern is important in affecting fragmentation effects. In the prefragmentation forest, gene flow across watersheds was possible, though less frequent than up/down rivers. After fragmentation, cross-watershed gene flow is much reduced. The resultant changes in genetic structure do not alter the $\mathrm{F}_{\mathrm{ST}}$ value, but greatly change the spatial arrangement of genetic variation, populations in the same valley becoming more alike, and populations in different valleys diverging. This result is not related to geographic distance (see populations 7, 8 and 9, and can only be interpreted with reference to landscape pattern. 
conditions in one year allow significant gene flow. Similarly, several years of high inbreeding rates may be complemented by a year of high outcrossing. The effect of increased variance in these process rates will obviously depend on the actual rates encountered interacting with the ecological characteristics of the species.

If population sizes and inter-population gene

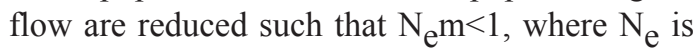
the effective population size and $\mathrm{m}$ is the migration rate, then inter-population genetic divergence will increase as remnant populations fix different alleles through random genetic drift (Wright 1931). This may change the pattern of response to future selection pressures. As genetic divergence increases, an increased proportion of the species genetic diversity is maintained among rather than within populations and so the population may become a significant unit of selection. Increased divergence may also limit overall ability to respond to new selection pressures as elevated species-level linkage disequilibrium will retard the generation of new multi-locus genotypes (Young 1995).

To date, two studies have examined whether ecosystem fragmentation leads to increased genetic divergence among remnant populations, both have used Acer saccharum (sugar maple) as a model system. In a comparison of allozyme diversity and genetic divergence among eight remnant Acer saccharum populations and eight intact populations in nearby forest, Young et al. (1993) found no increase in inter-population genetic divergence as a result of fragmentation. In fact, despite having $11 \%$ fewer alleles in total, the eight remnant populations exhibited elevated levels of allelic richness compared to intact populations. This, combined with an increase in the spread of alleles among remnant populations, actually pointed to increased inter-population gene flow subsequent to fragmentation.

In an earlier study, Foré et al. (1992) also used allozyme markers to compare inter-population genetic divergence between pre- and postfragmentation cohorts of fifteen Acer saccharum remnant populations. Genetic divergence among post-fragmentation cohorts was less than half that among pre-fragmentation cohorts, possibly indicating a reduction in genetic differentiation since fragmentation, presumably as a result of increased inter-population gene flow. More exhaustive inter-cohort comparisons on a subset of the same remnant populations showed the presence of alleles in post-fragmentation seedling cohorts that did not exist in their respective reproductive cohorts, providing clear evidence for sig- nificant inter-population gene flow after fragmentation (Ballal et al. 1994).

The idea that, at some scales, rather than resulting in increased genetic isolation, frag mentation leads to increased inter-population gene flow, a breakdown of local genetic structure, and possibly even elevated population-level genetic diversity is an interesting one. High within-population genetic diversity is generally desirable in terms of maximising evolutionary potential. Likewise, homogenisation of remnant population gene pools may mean that further population losses will have less of an effect on specieslevel genetic diversity than the original fragmentation event (Hamrick 1994).

Fragmentation may lead to reduced heterozygosity, either as a function of reduced population level variation and/or as a result of increased inbreeding. As with population-level variation, current empirical data suggest that reductions in population size due to ecosystem fragmentation are accompanied by reductions in average heterozygosity. However, whether this is a reflection of reduced population-level variation or increased inbreeding is not clear. For Eucalyptus albens no relationship was found between reproductive population size and the inbreeding coefficient that might explain the observed reduction in heterozygosity in small populations (Prober and Brown 1994). In contrast, small remnant populations of Gentiana pneuminanthe, which exhibited reduced levels of heterozygosity, did show elevated levels of inbreeding relative to larger more heterozygous populations (Raijmann et al. 1994). Explicit comparisons of outcrossing rates between large and small remnant populations of Salvia pratensis (Treuren et al. 1994) found no evidence of increased inbreeding in small populations of either species.

\section{Objectives}

a) To determine the effect of fragment size, isolation distance, matrix type, landscape pattern, ecology and reproductive biology of model species on the impact of fragmentation on initial loss of genetic diversity, and subsequent rates and variances of gene flow and inbreeding.

b) To construct a model to allow predictions to be made of the impact of fragmentation on genetic diversity.

\section{Methodology}

In the disturbance projects, model species will be used to examine variability in responses to fragmentation. Fragments will be located which rep- 
resent contrasting conditions for most of the factors, discussed above, likely to influence the impact of fragmentation. For each species, in each plot, genetic diversity of the mature individuals, embryos, seedlings, and possibly an intermediate cohort, will be determined, and mating system parameters estimated, by means of molecular markers. Population parameters for pollinator and seed-dispersal organisms will also be estimated.

The data will be analysed to investigate the relationship between distance of isolation and the various processes involved in conservation of genetic diversity.

\section{New molecular markers}

The effects of human activity on natural genepools (other than massive degradation through loss of forest cover) are of great scientific interest and of socio-economic importance if the genetic material is to be utilised. In the tropics man has been using, transporting and selecting some trees (particularly multi-purpose tree species) for millennia. There is great need for studies to quantify the effect of human interference on natural genepools rather than the present reliance on guesswork.

The genetic value of forest remnants as in situ conservation areas, minimum numbers of individuals and land area required to maintain population diversity is a subject of debate. Estimates of effective population size required for long term conservation of genetic resources vary (Franklin 1980; Namkoong et al. 1980). No one number will be applicable to all cases (Gilpin and Soulé 1986) and loss of alleles will always occur, except in populations of infinite size. Uneven sex ratios and long overlapping generations considerably reduce effective population size (Lande and Barrowclough 1987) and correspondingly increase the minimal area requirement (Soulé 1987), arguing for the use only of large undisturbed tracts of forest. Conversely others postulate that fragmentation will lead to increased gene flow between fragments and hence the maintenance or increase of within species diversity (Hamrick 1992). The use of molecular markers (isozymes and DNA) offer the possibility to directly measure genetic diversity and gene flow. Meaningful interpretation of results should however be based on information about all aspects of the reproductive biology of the species involved, including pollinators (Raw 1989; Boshier 1992).

As in other disciplines, the rapid advances in molecular techniques and their applications are revolutionising our capacity to recognise and interpret diversity. In forest systematics, population genetics and ecology, the established and emerging molecular technologies are beginning to be employed to address topics of fundamental concern to policy makers, forest managers and scientists. The proposed research will capitalise on recent developments in molecular biology, and progress their application in the systematics, population genetics and ecology of trees and forests.

This project involves the development of both theory and methodology, and substantial collaboration with researchers in the developing world; each offers a framework for training in both field and laboratory work. Applied studies will be based around sites and material which are already the subjects of advanced research, and from which we can therefore expect rapid progress. Fieldwork locations (initially Costa Rica, Honduras, Indonesia and Malaysia) have been selected to build on existing research capacity and collaborative partnerships.

The purpose of the basic element of the work will be the development of the next generation of molecular assays for tree taxa. These will be based on microsatellites, which are simple tandem base repeats that occur frequently and at random throughout most eukaryote genomes. Microsatellites represent "second generation" markers which are highly informative and offer several advantages over conventional molecular markers; in particular, they are inherited co-dominantly, which greatly increases their relevance to heterozygous tree taxa. Although already showing promise in human and mouse genome mapping projects, microsatellite markers have yet to be exploited in plant genome research; they have the potential to create high-resolution genetic maps for eventual exploitation in fundamental, strategic and applied research. As with the currently available randomly amplified polymorphic DNA (RAPDs), their use depends on amplifications through the polymerase chain reaction (PCR).

Markers are being applied to a number of problems in plant genetics. DNA-based approaches represent a basic shift in philosophy, from the inference of genotype from phenotype to a direct analysis of DNA sequence information, i.e., a change in emphasis from Mendelian to genomic genetics. Thus, DNA-based polymorphic assay procedures bring great speed, precision and accuracy to both the manipulation and analysis of genetic sources of variability. The perennial nature and long generation time of tree species indicate that DNA markers are likely to have a major impact with this group of largely 
outbreeding organisms.

The advent of polymerase chain reaction (PCR) accelerated the development and exploitation of new DNA marker systems. In contrast to Restriction Fragment Length Polymorphism (RFLP), PCR-based assays require only small amounts of genomic DNA, eliminate the need for Southern blotting and the use of radioactivity, and are compatible with the high throughput requirements of genome mapping and population genetics.

Williams et al. (1990) and Welsh and McClelland (1990) described the use of single, short oligonucleoide primers of arbitrary sequence for the amplification of randomly distributed segments of genomic DNA. The RAPD technique is based on the amplification of small, imperfect inverted repeats scattered throughout a genome and provides an innovative technology for DNA mapping and genome analysis. This advance has resulted in DNA marker technology being made more widely available to the scientific community, primarily because of its simplicity and the accessibility of synthetic oligonucleotides. RAPD polymorphisms are visualised as the presence or absence of an amplification product and are hence inherited in a dominant/recessive manner. The inability to identify heterozygotes is a serious drawback for the use of RAPDs in outbreeding species. The development and exploitation of co-dominant, highly polymorphic PCR-based markers is therefore considered a priority research area for heterozygous tree species.

Mammalian genome analysis has been revolutionised by the discovery of Simple Sequence Repeat (SSR) length polymorphism and its application to problems in mammalian genetics (Tautz 1989). Length polymorphisms within SSR or microsatellite loci are ubiquitous in eukaryotic genomes, highly polymorphic, and may be rapidly typed by PCR. Microsatellites are therefore considered to be ideal genetic makers for exploitation in fundamental and strategic research. Furthermore, primer sequences specific for a given microsatellite locus makes this technology available to the community without the need to distribute clones or other material. Such Sequence Tagged Sites (STS) provide a common language for collaborative research and are viewed as universal genetic mapping reagents.

The purpose of research on new molecular markers is to use microsatellite and complementary molecular techniques (variously isozymes, RAPDs, RFLPs) in studies across the spectrum of relevant research topics.

\section{Objectives}

(a) The development and application of molecular systematics;

To isolate polymorphic microsatellite loci in Gliricidia sepium or Bombacopis quinata (species choice to be confirmed);

To investigate the problems and level of allelic variation in geographically isolated populations; monitor gene flow and investigate mating system; and establish the utility of microsatellites for use in tree population genetics and studies of biological diversity (biodiversity).

(b) Application of these and other genetic markers to resolve questions in forest systematics, population genetics and ecology, specifically:

To undertake systematic studies of tree populations;

To investigate the effect of population fragmentation on intra-specific genetic diversity, mating system and gene flow; the relationship between intra-specific genetic diversity and population size spatial distribution; and, consequently, appropriate strategies for sampling and conservation.

(c) genetic and ecological perspectives on stand structure and dynamics:

To determine the genetic profiles of the seed and seedling banks and the mature population, and how the genetic composition of the seedling bank varies over time; (Temporal change encompasses both year of seeding (mast/ non-mast) and pre- and post-gap stages of development. We shall seek to investigate each of these parameters.)

To determine the extent to which the spatial arrangements of genotypes determines developmental success.

Clearly, some of these objectives are related to the complementary work on fragmentation, and will contribute to some of the objectives under that research topic.

\section{Methodology}

The effects of forest fragmentation on population genetic diversity and dynamics. Even if time were available, it would not be possible to study the change in diversity over time by artificially fragmenting the forest (cf. the Brazilian Amazon study by Lovejoy et al. 1986) as such pristine habitat no longer exists. To counter this, the project will try to study populations where there is evidence of their past status (plan of work, 1). The study of mating system, gene flow, etc. (plan of work, 6) may however, discriminate 
between populations with similar levels of diversity among parents but which are, in genetic terms, moving in opposite directions.

A number of factors favour the implementation of this study in the neo-tropical dry forests. These ecosystems include many economicallyimportant tree taxa, but they are highly threatened, with a consequent urgent need for effective genetic conservation. For the study to have wider relevance, it must consider taxa whose ecological and reproductive strategies cover the spectrum of possibilities; sufficient studies of reproductive biology of neo-tropical taxa have been completed to identify a representative range of species. Populations of these taxa exist across the spectrum of fragmentation, from undisturbed forest to isolated remnants. The contrasting reproductive and ecological factors used to define marker species are breeding systems (monoecious vs. dioecious, inbreeding vs. outbreeding), pollination and seed dispersal mechanisms (animal vs. wind vs. other), and successional status (pioneer vs. climax). A group of species which are known to span the range of these factors, and on which associated studies (e.g. systematics, reproductive biology) are already underway, will be used as marker taxa. The group of species investigated will comprise Bombacopsis guinata, Leucaena salvadorensis and Swietenia humilis. The study will assess genetic diversity and gene flow in up to three populations of each species in each of primary, mosaic and highly fragmented forests. Direct measures of genetic diversity and gene flow may be obtained using molecular techniques, while further studies of reproductive biology will be required to complete existing knowledge. Some work has been carried out on the reproductive biology and/or population genetics for some of the species (e.g., Bombacopsis quinata: Frankie et al. 1974; Leucaena salvadorensis: Sorensson 1989; Hellin and Hughes 1995; Swietenia humulis: Frankie et al. 1974; Lee 1967; Styles 1972).

Synthesising genetic and ecological perspectives on stand structure and dynamics. The structure and dynamics of plant populations reflect both genetic and ecological pressures. Genetic variation is a component of morphological and physiological variation, which in turn lead to variation in ecological performance (fitness) and, eventually, to changes in allelic frequencies over time. However, the disciplines of population genetics and ecology have had quite different perspectives: the former has emphasised the inter-related topics of population structure, genetic diversity and gene flow, and reproductive biology; the latter has focused on stand structure and regeneration dynamics. Thus, the link between allelic frequency and ecological adaptation has been little explored. Developments in molecular genetics, linked to co-ordinated ecological research, allow us to investigate, in genetic terms, the interaction between morphological, physiological and reproductive traits of trees, and their consequences for ecological success, illuminating questions such as the relationship between ecological and genetic sub-structuring of populations, and the nature of spatial and temporal change in genotype. This study would apply ecological and molecular genetic perspectives to studies of tropical-forest dynamics, providing knowledge of the interaction between genetic diversity and ecotypic variation. Clarification of the relationships between genetic diversity and ecological amplitude will considerably assist the management of natural forests.

Molecular genetic technologies will be used in conjunction with established techniques for eco-physiological investigations of regeneration and stand dynamics. It would be desirable in the longer run to conduct co-ordinated studies across a range of forest and site types, but we expect to begin work at a site in Sabah, with the assistance of local researchers and the Royal Society. Elsewhere, detailed ecological studies are under way in the moist forests of the Brazilian Amazon (CPATU/ODA) and Costa Rica (CATIE/ODA), where research focuses on six species from different ecological classes which are common to both sites; these studies would provide an excellent basis for subsequent research, if resources allow. Similarly, work could be extended to sites in Sri Lanka (University of Peradeniya/ODA), and co-ordinated with that in other South-East Asian dipterocarp forests. Genetic analyses would concentrate on the ecologically and commercially important species at each site.

\section{GIS}

The identification of optimum areas for conservation is increasingly reliant on computer technologies, such as GIS (Pressey et al. 1990; Margules et al. 1991; Vane-Wright et al. 1991). Such approaches may take the form of gap analyses (e.g. Scott et al. 1991) or the identification of minimum sets of conservation areas to meet a threshold value of some measurable variable (e.g., Margules et al. 1988; Margules and Kitching 1995). In most cases, the measurable variable is species richness, and the threshold value is some arbitrarily fixed proportion of total species richness within a region. Raw measures of species richness may be supplemented with 
assessments of threat to prioritise area selection or conservation effort (Dickman et al. 1993, Smith et al. 1993)

Some studies integrating socio-economic and biophysical data by means of GIS have been undertaken in relation to biodiversity conservation. For example, Fox et al. (1994a) investigated the conflict between grazing and conservation of red panda habitat in Langtang National Park in Nepal. A model of grazing impact was developed, which showed that the strong preference for gentle slopes and open canopies in selection of grazing lands coincided with prime red panda habitat. Fox et al. (1994b and c) also used GIS to study the farmer decision-making process in relation to biophysical and socio-economic variables, and temporal change in land use in northern Thailand.

Due to problems with measurement, the use of genetic diversity as a variable around which to design conservation areas has been rare. Millar and Westfall (1992) reviewed data on genetic diversity for twenty species of Californian conifer to recommend extensions to the existing protected area network. Their work did not include an assessment of threat to individual populations, and indeed there have been no examples of data on genetic diversity being combined with assessments of threat to determine a genetic conservation strategy.

Figure 8 illustrates how a model of threat could be combined with estimates of genetic diversity to design a truly integrated, effective and efficient genetic conservation programme. Only by integration of socio-economic and genetic data can the probability of continued survival of specific populations be assessed. The advantages of such an approach are many. Areas for extension of existing protected area networks can be identified based on some algorithm designed to maximise genetic diversity or differentiation, as was done by Millar and Westfall (1992). Beyond this, however, areas which may be useful additions to the protected area network, but which are under such intense threat that effective control is not possible, can be identified, thus avoiding wasted money and effort. These populations can then be subject to ex situ conservation measures. Indeed, the same approach can be used to set priorities for populations most deserving of ex situ conservation efforts. In this way, a comprehensive and co-ordinated genetic conservation programme, involving both in situ and ex situ conservation, can be developed.

It must be emphasised that the "threshold" line drawn in Figure 8 is not intended to imply that

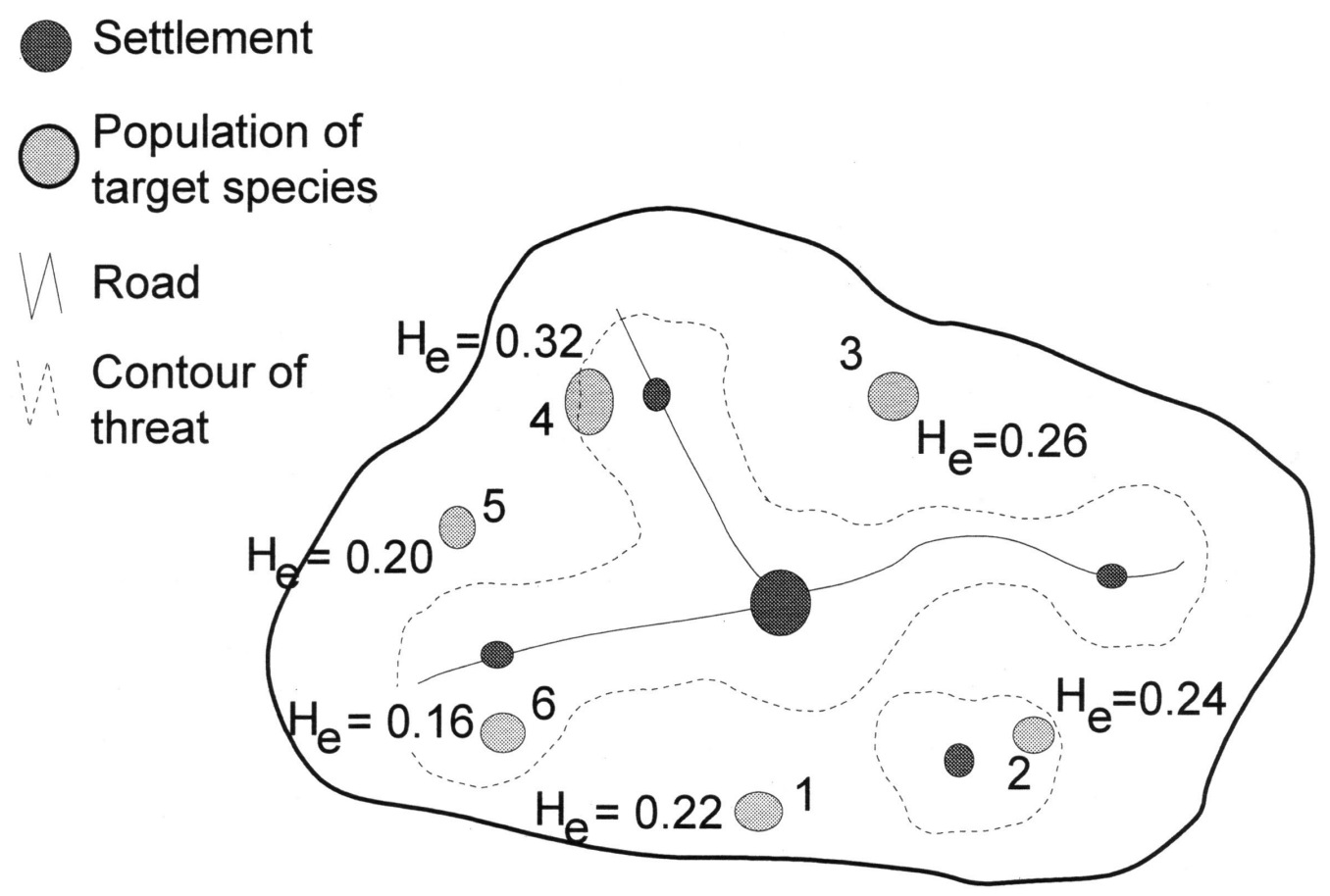

Figure 8. Hypothetical region (or country), showing roads, settlements, and target population of a species to be conserved. Modelling economic activities yields contours of threat, and a threshold level is shown. Without this information, priorities for in situ genetic conservation would be populations 4, 3, 2 , and 1. With the socio-economic model, priorities would be 3, 1, and 5. Populations 2 and 4 may be identified as priorities for ex situ conservation, if sufficiently genetically distinct from the sum of in situ populations. 
threat is static. The actual situation is complicated by the following factors:

a) threat is a dynamic phenomenon, affected by past land use and future developments in land prices, agricultural policies, etc., as well as social and cultural values;

b) threat will vary according to the value of the species - an unused species may be secure very close to settlements, whereas a highly valued species may be under great threat even deep in the forest; and

c) in any case, threat is a probabilistic measure, stated in terms of "an $\mathrm{x} \%$ chance of extinction within y years". What is an "acceptable" threat will then depend on the value of the resources. For a truly unique genetic resource, the chance of loss would need to be lower for in situ conservation to be considered as the only, or main, strategy.

\section{Objectives}

a) To develop a GIS-based system which, based on measures of genetic diversity and assessments of threat, prioritise genetic populations for both in situ and ex situ conservation

b) To demonstrate the applicability of the method by using data for one or two commercially important species

\section{Methodology}

Research projects could be developed in several regions. In Asia, data on genetic variation of both biochemical and quantitative traits has been collected from wide-ranging samples of Pterocarpus macrocarpus (Liengsiri et al. 1995) and Dalbergia cochinchinensis (Soonhuae et al. 1995) in Thailand. For both these species there is a longitudinal pattern of genetic differentiation, with superimposed local anomalies. Another CIFOR project is currently deriving statistics that will allow direct comparison of data from biochemical and quantitative traits, thus providing a valuable data set. Spatial information on forest cover and protected areas in Thailand is already available through WCMC's Biodiversity Map Library. To this information can be added digitised coverage of settlements and roads available at a 1:250,000 scale for the whole country, and at a 1:50,000 scale for central Thailand and parts of the northeast.

In Africa, OFI have conducted very detailed collections and genetic evaluations of six species of Acacia (Barnes et al. 1994). Field tests of several species are currently being established by the Zimbabwe Forestry Commission. This provides a very valuable set of genetic data. The situation concerning digitised maps of geographic and socio-economic variables is not known, but it is believed that, especially in Zimbabwe, the data sets already exist.

In Central America there is an excellent GIS unit at CATIE. This unit is rapidly inputting geographic and socio-economic data at a scale of $1: 100,000$ or better for several countries of the region. The quality of genetic data available is generally not as good as in SE Asia and southern Africa, but there is good information for mahogany (Swietenia spp.)

Wherever the projects are conducted, an assessment of threat to sampled populations will be developed, using a combination of factors, including proximity to a forest edge, proximity to a settlement or road, and location within or outside a protected area. An algorithm will then be developed which addresses two issues. Firstly, based on gap analysis, it will identify other populations that provide the greatest additional genetic diversity or differentiation to existing protected populations, while minimising total threat. At the same time, it will identify those populations which combine high genetic diversity with extreme threat, thus prioritising populations for ex situ conservation.

The major output of this research will be a generalisable system for developing a comprehensive genetic conservation strategy. As techniques for measuring genetic variation become quicker, cheaper and easier, the collection of the necessary genetic data required for operation of the system will be much simpler. By including a weighting of economic desirability of different species, it should be possible to design in situ conservation strategies that simultaneously take account of varying threats to different species within the same location, thus identifying species where supplemental ex situ conservation should be considered. The benefits of such a system to improved conservation techniques is obvious.

\section{New computer programs}

As mentioned in the Introduction, there is an urgent need for conservation of forest genetic resources. Breeders' intensified efforts in tree improvement will cause a higher levels of genetic uniformity in the breeding and production populations, especially for clonal forestry programmes. This increases the risk from pathogens (Namkoong 1986). Thus, tree breeders must also practise conservation of forest genetic resources (Ledig 1986). On the other hand, tree breeders are faced with the challenge to increase yield per unit area of land to compensate for the shrinking 
land base.

For both purposes - conservation of genetic diversity in natural forests and utilisation of genetic variation for increased productivity - an extensive knowledge and understanding of species population genetic structure is required.

To date, investigation of genetic structure in populations of forest trees has been based primarily on isozymes and, to a small degree, Restriction Fragment Length Polymorphisms (RFLPs) and Random Amplified Polymorphic DNAs (RAPDs). The advantages of these techniques are their ability to detect variation at individual genes (Brown and Moran 1981). The modern renaissance of evolutionary quantitative genetics (Lande 1988), however, has enhanced our understanding of the evolutionary forces that maintain heritable quantitative variation. Quantitative traits are often controlled by many genes, each of which may have relatively limited effects. While direct characterisation of individual genes is not possible for quantitative traits, their existence can be inferred from estimation of genetic variance (Yang et al. 1996). This has important implications for forest trees due to the existence of an extensive morphological database derived from field tests.

Although isozymes and DNA markers have permitted an understanding of population genetic structure, their practical value in tree improvement and gene conservation also depend on their adaptive significance and how such variation correlates with variation in quantitative traits. Correlation between isozyme and quantitative variation was first predicted by Lerner (1954) based on his observation of the relationship between heterozygosity, growth rate and developmental homeostasis in plants and animals. However, such a relationship is unclear for forest trees. Positive correlations between number of heterozygous allozyme loci and fitness-related traits have been reported (e.g., Ledig et al. 1983; Linhart and Mitton 1985; Strauss 1986), but other studies showed either no or negative correlations (e.g., Bush et al. 1987; Linhart et al. 1989). The existence of gene co-adaptation in such studies can cause this inconsistency; for example, a fitness-related trait such as drought-response is controlled by a block of co-adapted gene complexes in some species (Yang et al. 1991).

If we are to be able to relate quantitative variation to isozyme and DNA variation, it is imperative that we know whether there is random or non-random association of genes at isozyme and DNA loci (i.e., multi-locus structure). Therefore we must determine if gene co-adaptation (i.e., multi-locus structure) exists for isozymes and
DNA markers.

Currently, there are thousands of field trials of forest trees established around the world, for which standard analyses of observed variation may have been conducted. Many of these trials could provide valuable data on population genetic structure, but user-friendly packages allowing such analyses are not available. Similarly, there is a growing body of data on biochemical and molecular genetic variation, which is also underutilised. With the application of analytical techniques recently developed at the University of Alberta (e.g., Yang et al. 1991, Yang et al. 1996), quantitative and biochemical/molecular data can provide much more valuable information on population genetic structure, thus promoting the development of more effective conservation strategies, and the acceleration of genetic improvement programmes.

\section{Objectives}

To integrate population genetics statistics developed for isozymes (Yang and Yeh 1993; Yeh et al. 1994), RAPDs (Chong et al. 1994) and quantitative traits. (Yang et al. 1996) into a user-friendly, Windows-based computer package that characterises genetic diversities and their apportionments to the within- and among-population components. Specifically this computer package will enable:

a) Characterisation of single and multi-locus genetic structure in natural populations from analyses of isozymes, RFLPs or RAPDs;

b) Characterisation of the genetic structure of natural populations from analyses of quantitative traits; and

c) Tests for the selective significance of isozymes, RFLPs, RAPDs or quantitative traits.

\section{Methodology}

a) Characterisation and multi-locus genetic structure based on isozymes, RFLPs and RAPDs: Statistical analyses of genetic structure based on the average of single-locus estimates will follow that of allelic and genotypic data described for isozymes (e.g., Yeh et al. 1985), RFLPs (e.g., Hong et al. 1993) and RAPDs (e.g., Chong et al. 1994). Testing for multilocus structure in the past was limited to contingency table analysis of pairs of loci (e.g., Yeh and Morgan 1987). Apart from the inherent statistical problem of frequency-dependence (Lewontin 1988), the required number of pair-wise tests become prohibitively large when there are a large number of loci, each 
having many alleles. Here, we will adopt two sets of summary statistics that adequately characterise multi-locus structure in natural populations of forest trees from analyses of sozyme data (Yang and Yeh 1993; Yeh et al. 1994). These statistics are also applicable to RFLPs and they are most suitable for RAPDs because of the large number of marker loci in such studies.

b) Characterisation of the genetic structure of natural populations from analyses of quantitative traits: The analysis of genetic structure based on the F-statistics of Wright (1951) will follow that described for quantitative traits in Pinus contorta ssp latifolia (Yang et al. 1996). In addition to partitioning of quantitative variations to the among- and within-population components, our package will also provide estimates of population, family and individual heritabilities and their respective standard errors.

c) Tests for the selective significance of isozymes RFLPs or quantitative traits: The adaptive significance of isozymes, RFLPs, and RAPDs is evaluated from the Ewens-Watterson test for neutrality (Manly 1985). Confidence intervals of $\mathrm{F}_{\text {St }}$ (Wright 1965) for isozymes, RFLPs, and RAPDs are derived from bootstrapping (Yang et al. 1996). The relative importance of two major forces in population differentiation - natural selection and drift is deducted from a comparison of $\mathrm{F}_{\mathrm{St}}$ estimates from quantitative traits and $\mathrm{F}_{\mathrm{St}}$ from isozymes, RFLPs, and/or RAPDs (Yang et al. 1996).

\section{Acknowledgements}

I would like to thank Abdou-Salam Ouedraogo (IPGRI), Peter Kanowski (Australian National University), Francis Yeh (University of Alberta), Andrew Young (CSIRO), Thomas Enters (CIFOR), Steve Harris and David Boshier (OFI) for contributions to the text; and Thomas Enters, Jeff Sayer and John Turnbull for comments on earlier versions of the manuscript.

\section{References}

Ackerly, D.D., J.M. Rankin-de-Merona and W.A. Rodrigues. 1990. Tree densities and sex ratios in breeding populations of dioecious Central Amazonian Myristiceae. Journal of Tropical Ecology 6: 239248.

Ballal, S.R., S.A. Foré and S.I. Guttman. 1994. Apparent gene flow and genetic structure of Acer saccharum subpopulations in forest fragments. Canadian Journal of Botany 72:1311-1315.

Barnes, R.D., D.L. Filer, L.A. Lockhart and I.D. Gourlay. 1994. Acacia karroo: Evaluation and assembly of genetic resources. ODA Forestry Research Scheme R.4526, Final Report. Oxford Forestry Institute.

Billington, H.L. 1991. Effect of population on genetic variation in a dioecious conifer. Conservation Biology 5:115-119.

Boshier, D.H. 1992. Cordia alliodora: a fuller picture of reproductive biology. Invited paper, presented at IUFRO conference on breeding tropical trees, Cartagena-Cali, Colombia, 9-18th October, 1992.

Boyle, T.J.B., C. Cossalter, and A.R. Griffin. (in press). Genetic resources for plantation forestry. In: S. Nambiar, A. Brown and C. Cossalter (eds) Management of Soil and Water in Tropical Forest Plantations. ACIAR, Canberra. Chapter 2.

Boyle, T.J.B. and J.A. Sayer. 1995. Measuring, monitoring and conserving biodiversity in managed tropical forests. Commonwealth Forestry Review. 74: 20-25.

Braatz, S. 1992. Conserving Biological Diversity. A Strategy for Protected Areas in the Asia-Pacific Region. World Bank Technical Paper Number 193. Asia Technical Department Series, The World Bank, Washington, DC.

Brenes Varela, G. 1994. Descripcion general del programa de restauracion y silvicultura del bosque seco del area de conservacion Guanacaste. Ministerio de Recursos Naturales Energia y Minas, Liberia, Costa Rica.

Brown, A.H.D. and G.F. Moran. 1981. Isozymes and the genetic resources of forest trees. In M.T. Conkle (ed.), Proceedings of Symposium on Isozymes of North American Forest Trees and Insects. US Forest Service Technical Report PSW-48, pp. 1-10. 
Bush, R.M., P.E. Smouse and F.T. Ledig. 1987. The fitness consequences of multiple-locus heterozygosity: The relationship between heterozygosity and growth rate in pitch pine (Pinus rigida Mill.). Evolution 41: 787-798.

Chong, D.K.X, F.C. Yeh and R.C. Yang. 1994. Nucleotide divergence between populations of trembling aspen (Populus tremuloides) estimated with RAPDs. Current Genetics 26: 374-376.

CIFOR (Center for International Forestry Research). 1996. CIFOR: A strategy for collaborative research (Draft). CIFOR, Jakarta.

Dickman, C.R., R.L. Pressey, L. Lim and H.A. Parnaby. 1993. Mammals of particular conservation concern in the Western Division of NSW. Biological Conservation 65: 219-248.

Fairhead, J. and M. Leach. 1993. Contested Forests: Modern Conservation and Historical Land Use of Guineas Ziama Reserve. Working paper 7, Connaissance et Organisation Locales Agroecologiques (COLA), Kissidougou (Guinea).

Foré, S.A., R.J. Hickey, J.L. Vankat, S.I. Guttman and R.L. Schaefer. 1992. Genetic structure after forest fragmentation: a landscape ecology perspective on Acer saccharum. Canadian Journal of Botany 70: 1659-1668.

Fox, J., P. Yonzon and N. Podger. 1994a. Maps, yaks, and red pandas: using GIS to model conflicts between biodiversity and human needs. In: J. Fox (ed.), Spatial Information and Ethnoecology: Case Studies from Indonesia, Nepal, and Thailand. East-West Center Working Paper, Environment Series No. 38. East-West Center, Honolulu. pp. 15-26.

Fox, J., R. Kanter, S. Yarnasarn, M. Elkasingh and R. Jones. 1994b. Farmer decision making and spatial variables in northern Thailand. Environmental Management 18: 391-399.

Fox, J., J. Krummel, S. Yarnasarn, M. Ekasingh and N. Podger. 1994c. Land use and landscape dynamics in northern Thailand: assessing change in three upland watersheds since 1954. In: J. Fox (ed.), Spatial Information and Ethnoecology: Case Studies from Indonesia, Nepal, and Thailand. EastWest Center Working Paper, Environment Series No. 38. East-West Center, Honolulu. pp. 27-42.

Frankel, O.H. 1970. Variation - the essence of life. Sir William Macleay Memorial Lecture. Proceedings of the Linnean Society of New South Wales 95: 158-169.

Frankel, O.H. 1974. Genetic conservation: our evolutionary responsibility. Genetics 78: 53-65.

Frankie, G.W., H.G. Baker and P.A. Opler. 1974. Comparative phenological studies of trees in tropical wet and dry forests in the lowlands of Costa Rica. Journal of Ecology 62: 881-919.

Frankie, G.W., W.A. Haber, P.A. Opler and K.S. Bawa. 1983. Characteristics and organization of the large bee pollination system in the Costa Rican dry forest. In: C.E. Jones and R.J. Little (eds), Handbook of Experimental Pollination Biology. Van Nostrand Reinhold, New York.. pp. 411-447.

Franklin, L.R. 1980. Evolutionary change in small populations. In: M.E. Soulé and B.A. Wilcox (eds), Conservation Biology: An Evolutionary-Ecological Perspective. Sinauer Assocs., Sunderland, Mass., USA. pp. 135-149.

Gilpin, M.E. and M.E. Soulé. 1986. Minimum viable populations: processes of species extinctions. In: Soulé, M.E. (ed.), Conservation Biology: The Science of Scarcity and Diversity. Sinauer Assocs., Sunderland, Mass., USA. pp. 19-34.

Gómez-Pompa, A. and A. Kaus. 1992. Taming the wilderness myth. BioScience 42: 271-279.

Hamrick, J.L. 1992. Distribution of genetic diversity in tropical tree populations: implications for the conservation of genetic resources. IUFRO conference on breeding tropical trees, Cartagena-Cali, Colombia, 9-18th October, 1992.

Hamrick, J.L. 1994. Genetic diversity and conservation in tropical forests. In: R.M. Drysdale, S.E.T. John and A. Yapa (eds), Proceedings: International Symposium on Genetic Conservation and Production of Tropical Forest Seed. ASEAN Canada Forest Tree Seed Centre, Muak Lek, Thailand. pp. 1-9.

Hartl, D.L. and A.G. Clark. 1989. Principles of Population Genetics. Sinauer Assocs., Sunderland, Mass., USA.

Hellin, J.J. and C.E. Hughes. 1995. Leucaena salvadorensis: Conservation and Utilization in Central America. CONSEFORH, Honduras.

Helliwell, D.R. 1976. The effects of size and isolation on the conservation value of wooded sites in Britain. Journal of Biogeography 3: 407-416. 
Hong Y. P., V.D. Hipkins and S.H. Strauss. 1993. Chloroplast DNA diversity among trees, populations and species in the California closed-cone pine (Pinus radiata, Pinus muricata and Pinus attenuata). Genetics 135: 1187-1196.

Janssen, W. and P. Goldsworthy. 1995. Multidisciplinary Research for Natural Resource Management: Conceptual and Practical Implications. ISNAR, The Hague.

Lande, R. 1988. Quantitative genetics and evolution theory. In: B.S. Weir, F.J. Eisen, M.M. Goodman and G. Namkoong (eds), Proceedings of the 2nd International Conference on Quantitative Genetics. Sinauer Assocs., Sunderland, Mass., USA. pp. 71-84.

Lande, R. and G.F. Barrowclough. 1987. Effective population size, genetic variation and their use in population management. In: M.E. Soulé (ed.), Viable Populations for Conservation. Cambridge University Press, Cambridge, UK pp. 87-123.

Ledig , F. T., R.P. Guries, and B.A. Bonefeld. 1983. The relation of growth to heterozygosity in pitch pine. Evolution 37: 1227-1238.

Ledig, F.T. 1986. Conservation strategies for forest gene resources. Forest Ecology and Management 14: $77-90$.

Ledig, F.T. 1992. Human impacts on genetic diversity in forest ecosystems. Oikos 63: 87-108.

Lee, H.Y. 1967. Studies in Swietenia (Meliaceae): Observations on the sexuality of the flowers. J. Am Arb. 48: 101-104.

Lerner, I.M. 1954. Genetic Homeostasis. Oliver and Boyd, London.

Lewontin, R.C. 1988. On measures of gametic disequilibrium. Genetics 120: 849-852.

Liengsiri, C., F.C. Yeh and T.J.B. Boyle. 1995. Genetic structure of a tropical forest tree: Pterocarpus macrocarpus Kurz. in Thailand. Forest Ecology and Management 74: 13-22.

Linhart, Y.B. and J.B. Mitton. 1985. Relationships among reproduction, growth rates, and genetic protein heterozygosity in ponderosa pine. American Journal of Botany 72: 181-184.

Linhart, Y.B., M.C. Grant, and P. Montazer. 1989. Experimental studies in ponderosa pine. 1. Relationship between variation in proteins and morphology. American Journal of Botany 76: 1024-1032.

Lovejoy, T. E., R.O. Bierregaard Jr., A.B. Rylands, J.R. Malcolm, C.E. Quintella, L.H. Harper, K.S. Brown Jr., A.H. Powell, G.V.N. Powell, H.O.R. Shubart and M.B. Hays. 1986. Edge and other effects of isolation on Amazon forest fragments. In: M.E. Soulé (ed.), Conservation Biology: The Science of Scarcity and Diversity. Sinauer Assocs., Sunderland, Mass. USA. pp. 257-285.

Machlis, G.E. 1992. The contribution of sociology to biodiversity research and management. Biological Conservation 62: 161-170.

Margules, C.R. and Kitching, I.J. 1995. Assessing priority areas for biodiversity and protected area networks. In: T.J.B. Boyle and B. Boontawee (eds), Measuring and Monitoring Biodiversity in Tropical and Temperate Forests. CIFOR, Bogor, Indonesia. pp. 355-364.

Margules, C.R., A.O. Nicholls and R.L. Pressey. 1988. Selecting networks of reserves to maximize biological diversity. Biological Conservation 43: 663-676.

Margules, C.R., R.L. Pressey and A.O. Nicholls. 1991. Selecting nature reserves. In: C.R. Margules and M.P. Austin (eds.). Nature Conservation: Cost Effective Biological Surveys and Data Analysis. CSIRO, Melbourne. pp. 90-97.

McNeely, J.A. 1993. Economic Incentives for Conserving Biodiversity: Lessons from Africa. Ambio 22: 144-150.

Meave, J, M. Kellman, A. MacDougall and J. Rosales. 1991. Riparian habitats as tropical forest refugia. Global Ecology and Biogeography Letters 1: 69-76.

Melynk, M. 1994. Biodiversitys contribution to rural livelihoods - a component of environmental impact assessment. In: A.F. Krattiger, J.A. McNeely, W.H. Lesser, K. R. Miller, Y. St. Hill, and R. Senanayake (eds), Widening Perspectives on Biodiversity. International Academy of the Environment, Geneva and The World Conservation Union, Gland. pp. 347-351.

Millar, C.I. and R.D. Westfall. 1992. Allozyme markers in forest genetic conservation. In: W.T. Adams, S.H. Strauss, D.L. Copes and A.R. Griffin (eds), Population Genetics of Forest Trees. Kluwer Academic, Dordrecht. pp. 347-372. 
Moran, G. F. and S.D. Hopper. 1987. Conservation of the Genetic Resources of Rare and Widespread Eucalypts in Remnant Vegetation. In: D.A. Saunders, G.W. Arnold, A.A. Burbridge and J.A. Hopkins (eds), Nature Conservation - The Role of Remnants of Nature Vegetation. Surrey Beatry and Sons Ltd., Australia. pp. 151-162.

Murawski, D.A. and J.L. Hamrick. 1991. The effect of the density of flowering individuals on the mating systems of nine tropical tree species. Heredity 67: 167-174.

Murawski, D.A., I.A.U.N. Gunatilleke and K.S. Bawa. 1994. The effects of selective logging on inbreeding in Shorea megistophylla (Dipterocarpaceae) from Sri Lanka. Conservation-Biology 8: 9971002.

Namkoong, G. 1986. Genetics and the forests of the future. Unasylva 38: 2-18.

Namkoong, G., R.D. Barnes and J. Burley. 1980. A Philosophy of Breeding Strategy. Tropical Forestry Paper no. 16. University of Oxford, Oxford, UK National Research Council. 1991. Managing Global Genetic Resources: Forest Trees. National Academy Press, Washington, D.C.

Panayotou, T. and D. Glover. 1994. Economic and financial incentives for biodiversity conservation and development. Paper commissioned by IUCN for Presentation at the Regional Conference on Biodiversity Conservation. Asian Development Bank, June 6 - 8, 1994.

Panayotou, T. and P.S. Ashton. 1992. Not By Timber Alone. Economics and Ecology for Sustaining Tropical Forests. Island Press, Washington, DC.

Pinedo-Vasquez, M. and C. Padoch. 1993. Community and governmental experiences protecting biodiversity in the lowland Peruvian Amazon. In: C.S. Potter, J.I. Cohen and D. Janczewski (eds), Perspectives on Biodiversity: Case Studies of Genetic Resource Conservation and Development. AAAS Press, Washington, DC. pp. 199-211.

Powell, A.H. and G.V.N. Powell. 1987. Population dynamics of male euglossine bees in Amazonian forest fragments.. Biotropica 19: 176-179.

Pressey, R.L., M. Bedward and A.O. Nicholls. 1990. Reserve selection in mallee lands. In: J.C. Noble, P.J. Joss and G.K. Jones (eds), The Mallee Lands: A Conservation Perspective. CSIRO, Melbourne. pp. 167-178.

Primack, R.B. 1993. Essentials of Conservation Biology. Sinauer Assocs., Sunderland, Mass., USA.

Prober, S.M. and A.H.D. Brown. 1994. Conservation of the grassy white box woodlands: population genetics and fragmentation of Eucalyptus albens. Conservation Biology 8: 1003-1013.

Raijmann L.L., N.C. Vanleeuwen, R. Kersten, J.G.B. Oostermeijer, H.C.M. Dennijs and S.B.J. Menken. 1994. Genetic variation and outcrossing rate in relation to population size in Gentiana pneumonanthe L. Conservation Biology. 8: 1014-1026.

Rajasekaran, B. and D.M. Warren. 1994. IK for socioeconomic development and biodiversity conservation: the Kolli Hills. Indigenous Knowledge \& Development Monitor 2: 13-17.

Raw, A. 1989. The dispersal of euglossine bees between isolated patches of eastern Brazilian wet forest (Hymenoptera, Apidae). Revista Brasileira De Entomologia 33: 103-107.

Scoones, I. and F. Matose. 1993. Local woodland management: constraints and opportunities for sustainable resource use. In: P.N. Bradley and K. McNamara (eds), Living with Trees: Policies for Forestry Management in Zimbabwe. World Bank Technical Paper 210, Washington, DC. pp. 157198.

Scott, J.M., B. Csuti and S. Ciacco. 1991. Gap analysis: assessing protection needs. In: W.E. Hudson (ed.), Landscape linkages and biodiversity. Island Press, Washington DC.

Shafer, C.L. 1990. Nature Reserves. Island Theory and Conservation Practices. Smithsonian Institute Press, Washington and London.Silver. 1992.

Smith, P.J., R.L. Pressey and J.E. Smith. 1993. Birds of particular conservation concern in the Western Division of NSW. Biological Conservation 69: 315-338.

Soonhuae, P., T.J.B. Boyle, T. and F.C. Yeh. 1995. The population genetics of Dalbergia cochinchinensis Pierre and implications for genetic conservation. Proceedings of the IUFRO Symposium "Population genetics and gene conservation of forest trees". Carcans Maubuisson, France.

Sorensson, C.T. 1989. Status and mechanisms of self-incompatibility and selfcompatibility in Leucaena species. Plant Cell Incompatibility Newsletter 21: 77-85. 
Soulé, M.E. (ed.). 1987. Viable Populations for Conservation. Cambridge University Press, Cambridge, UK.

Strauss, S.H. 1986. Heterosis at allozyme loci under inbreeding and crossbreeding in Pinus attenuata. Genetics 113: 115-134

Styles, B.T. 1972. The flower biology of the Meliaceae and its bearing on tree breeding. Silvae Genetica 21: $175-18$.

Tautz, D. 1989. Hypervariability of simple sequences as a general source for polymorphic DNA markers. Nucleic Acids Research 17: 6463-6471.

Tenenbaum, D. 1994. The Guanacaste idea. American Forests, Nov./Dec.: 28-31 and 58-59.

Tsai, L.M. and C.T. Yuan. 1995. A practical approach to conservation of genetic diversity in Malaysia: genetic resource area. In: Boyle, T.J.B. and B. Boontawee (eds.). Measuring and monitoring biodiversity in tropical and temperate forests. CIFOR, Bogor, Indonesia. pp. 207-217.

Utting, P. 1993. Trees, People and Power. Earthscan Publications Ltd, London.

Vanclay, J.K. 1992. Species Richness and Productive Forest Management. In: F.R Miller and K.L. Adam.(eds), Wise Management of Tropical Forests. Proceedings of the Oxford Conference on Tropical Forests 1992. OFI, Oxford. pp. 1-9.

Vane-Wright, R.I., C.J. Humphries and P.H. Williams. 1991. What to protect? - systematics and the agony of choice. Biological Conservation 55: 235-54.

Vantreuren, R., R. Bijlsma, N.J. Ouborg and W. Vandelden. 1993. The efects of population size and plant density on outcrossing rates in locally endangered Salvia pratensis. Evolution 47 (4):1094-1104.

Vantreuren, R., R. Bijlsma, N.J. Ouborg and M.M. Kwak. 1994. Relationships between plant density, outcrossing rates and seed set in natural and experimental populations of Scabiosa columbaria. Journal of Evolutionary Biology. 7 (3):287-302.

Weir, B.S., F. J. Eisen, M.M. Goodman and G. Namkoong (editors). 1988. Proceedings of the 2nd International Conference on Quantitative Genetics. Sinauer Assocs., Sunderland, Mass., USA.

Wells, M.P. and K.E. Brandon. 1993. The principles and practices of buffer zones and local participation in biodiversity conservation. Ambio 22: 157-162.

Welsh J. and M. McClelland. 1990. Fingerprinting genomes using PCR with arbitrary primers. Nucleic Acids Research 18: 7213-7218.

Williams J.G.K, A.R. Kubelik, K.J. Livak, A. Rafalski and S.V. Tingey. 1990. DNA polymorphisms amplified by arbitrary primers are useful as genetic markers. Nucleic Acids Research 18: 65136535 .

Woods, D. 1994. Conservation and agriculture: the need for a new international network of biodiversity and development institutes to resolve conflicts. In: A.F. Krattiger, J.A. McNeely, W.H. Lesser, K. R. Miller, Y. St. Hill, Y. and Senanayake R. (eds), Widening Perspectives on Biodiversity. International Academy of the Environment, Geneva and The World Conservation Union, Gland. pp. 425-434.

Wright, S. 1931. Evolution in a Mendelian population. Genetics 16: 97-159.

Wright S. 1951. The genetic structure of populations. Annals of Eugenics 15: 323-354.

Wright S. 1965. Interpretation of population structure by F-statistics with special regard to systems of mating. Evolution 19: 395-420.

Yang, R.-C. and F.C. Yeh. 1993. Multilocus structure of lodgepole pine (Pinus contorta Dougl.). Theoretical and Applied Genetics 87: 568-576.

Yang, R.-C., S. Jana, and J.M. Clarke. 1991. Phenotypic diversity and associations of some potentially drought-responsive characters in durum wheat. Crop Science 31: 1484-1491.

Yang, R.C., F.C. Yeh and A Yanchuk. 1996. A comparison of isozymes and quantitative variation in Pinus contorta spp. latifolia by $\mathrm{F}_{\mathrm{st}}$. Genetics 142:

Yeh, F. C., J.S. Shi, R.C. Yang, J.S. Hong and Z.H. Ye. 1994. Genetic diversity and multilocus associations in Cunninghamia lanceolata (Lamb.) Hook from People's Republic of China. Theoretical and Applied Genetics 88:465-471.

Yeh, F.C. and K. Morgan. 1987. Mating system and multilocus associations in a natural population of Pseudotsuga menziesii (Mirb.) Franco. Theoretical and Applied Genetics 73: 799-808. 
Yeh, F.C., W.M. Cheliak, B.P. Dancik, K. Illingworth D.C. Trust and B.A. Pryhitka. 1985. Population differentiation in lodgepole pine. Pinus contorta spp. latifolia: a discriminant analysis of allozyme variation. Canadian Journal of Genetics and Cytology 27: 210-218.

Young, A.G. and N. Mitchell. 1994. Microclimate and vegetation edge effects in a fragmented podocarpbroadleaf forest in New Zealand. Biological Conservation 67: 63-72.

Young, A.G. 1995. Forest fragmentation: effects on population genetics processes. Proceedings of the XX IUFRO World Congress (in press).

Young, A.G. and T.J.B. Boyle. (in press). Genetic consequences of ecosystem fragmentation for plants. Trends in Ecology and Evolution.

Young, A.G. and H.G. Merriam. 1995. The spatial genetic structure of Acer saccharum Marsh. (sugar maple) and its implications for conservation. Proceedings of the IUFRO Symposium. "Population genetics and gene conservation of forest tees". Carcans Maubuisson, France.

Young, A.G., H.G. Merriam and S.I. Warwick. 1993. The effects of forest fragmentation on genetic variation in Acer saccharum Marsh. (sugar maple) populations. Heredity 71: 277-289. 